\title{
Nicotinic Acetylcholine Receptor Accessory Subunits Determine the Activity Profile of Epibatidine Derivatives $\$$
}

\author{
Lu Wenchi Corrie, Clare Stokes, (1) Jenny L. Wilkerson, F. Ivy Carroll, Lance R. McMahon, \\ and Roger L. Papke
}

Department of Pharmacology and Therapeutics, College of Medicine (L.W.C., C.S., R.L.P.) and Department of

Pharmacodynamics, College of Pharmacy, (J.L.W., L.R.M.), University of Florida, Gainesville, Florida; and Center for Drug

Discovery, Research Triangle Institute, Durham, North Carolina (F.I.C.)

Received April 10, 2020; accepted July 2, 2020

\section{ABSTRACT}

Epibatidine is a potent analgetic agent with very high affinity for brain nicotinic acetylcholine receptors (nAChR). We determined the activity profiles of three epibatidine derivatives, RTI-36, RTI76 , and RTI-102, which have affinity for brain $n A C h R$ equivalent to that of epibatidine but reduced analgetic activity. RNAs coding for nAChR monomeric subunits and/or concatamers were injected into Xenopus oocytes to obtain receptors of defined subunit composition and stoichiometry. The epibatidine analogs produced protracted activation of high sensitivity (HS) $\alpha 4$ - and $\alpha 2$-containing receptors with the stoichiometry of 2alpha:3beta subunits but not low sensitivity (LS) receptors with the reverse ratio of alpha and beta subunits. Although not strongly activated by the epibatidine analogs, LS $\alpha 4$ - and $\alpha 2-$ containing receptors were potently desensitized by the epibatidine analogs. In general, the responses of $\alpha 4(2) \beta 2(2) \alpha 5$ and $\beta 3 \alpha 4 \beta 2 \alpha 6 \beta 2$ receptors were similar to those of the HS $\alpha 4 \beta 2$ receptors. $\mathrm{RTI}-36$, the analog closest in structure to epibatidine, was the most efficacious of the three compounds, also effectively activating $\alpha 7$ and $\alpha 3 \beta 4$ receptors, albeit with lower potency and less desensitizing effect. Although not the most efficacious agonist, RTI-76 was the most potent desensitizer of $\alpha 4$ - and $\alpha 2$-containing receptors. RTI-102, a strong partial agonist for HS $\alpha 4 \beta 2$ receptors, was effectively an antagonist for LS $\alpha 4 \beta 2$ receptors. Our results highlight the importance of subunit stoichiometry and the presence or absence of specific accessory subunits for determining the activity of these drugs on brain nAChR, affecting the interpretation of in vivo studies since in most cases these structural details are not known.

\section{SIGNIFICANCE STATEMENT}

Epibatidine and related compounds are potent ligands for the high-affinity nicotine receptors of the brain, which are therapeutic targets and mediators of nicotine addiction. Far from being a homogeneous population, these receptors are diverse in subunit composition and vary in subunit stoichiometry. We show the importance of these structural details for drug activity profiles, which present a challenge for the interpretation of in vivo experiments since conventional methods, such as in situ hybridization and immunohistochemistry, cannot illuminate these details.

\section{Introduction}

Nicotinic acetylcholine receptors (nAChR), first characterized at the neuromuscular junction (Papke, 2014), assemble as pentameric complexes of subunits and function as ligand-gated ion channels, activated by acetylcholine (ACh) or exogenous drugs like nicotine. In total, nine different $\alpha$ subunits $(\alpha 2-\alpha 10)$ identified by the presence of a pair of vicinal cysteines, and three nonalpha subunits $(\beta 2-\beta 4)$ have been found expressed in vertebrate neuronal tissues.

Functional heteromeric receptors form readily from the coexpression of $\alpha 2, \alpha 3$, or $\alpha 4$ with either $\beta 2$ or $\beta 4$ (Papke,

This work was support by the National Institutes of Health National Institute of General Medical Sciences [Grant GM57481] and National Institute on Drug Abuse [Grants DA47855 and DA48353].

https://doi.org/10.1124/molpharm.120.000037.

S This article has supplemental material available at molpharm. aspetjournals.org.
2014), with each $\alpha-\beta$ pair forming ACh binding sites with unique functional and pharmacological properties (Luetje and Patrick, 1991; Papke et al., 1989, 2010, 2013; Papke and Heinemann, 1991). The structurally required fifth subunit can be either an $\alpha$ or $\beta$ subunit. Beginning with single-channel study of heterologously expressed neuronal nAChR, it was shown that the ratio of $\alpha$ to $\beta$ subunits was important for determining receptor properties (Papke et al., 1989). Subsequent studies have confirmed the importance of the specific subunit composition (Nelson et al., 2003; Kuryatov et al., 2008; Jain et al., 2016; Lucero et al., 2016). Although not contributing to ACh binding sites, $\alpha 5$ and $\beta 3$ subunits can be functionally important in receptors, taking the accessory subunit position, with $\beta 3$ especially important for $\alpha 6$ containing receptors in dopaminergic neurons (Gerzanich et al., 1997, 1998; Kuryatov et al., 2000; Kuryatov and Lindstrom, 2011). Alpha3 subunits will form functional heteromeric receptors with either $\beta 2$ or $\beta 4$ subunits (Papke

ABBREVIATIONS: ACh, acetylcholine; HS, high sensitivity; LS, low sensitivity; nAChR, nicotinic acetylcholine receptor; RTI-36, 2-(6-chloropyridin3-yl)-7-azabicyclo[2.2.1] heptane; (epibatidine), 2'-fluorodeschloroepibatidine; RTI-76, 3'-(3"-dimethylaminophenyl)-epibatidine; RTI-102, 2'-fluoro3'-(4-nitrophenyl)deschloro-epibatidine. 
TABLE 1

Previous studies of epibatidine human nAChR expressed in oocytes

\begin{tabular}{|c|c|c|}
\hline & $\begin{array}{c}\mathrm{EC}_{50} \\
\mu \mathrm{M}\end{array}$ & $I_{\max }$ \\
\hline \multicolumn{3}{|c|}{ Data from Gerzanich et al. (1995) } \\
\hline \multicolumn{3}{|c|}{$\alpha 3 \beta 4$ (formed by $1: 1$ expression of monomers) } \\
\hline (+)Epibatidine & $0.073 \pm 0.006$ & \\
\hline (-)Epibatidine & $0.021 \pm 0.007$ & \\
\hline Nicotine & $110 \pm 4.0$ & \\
\hline $\mathrm{ACh}$ & $160 \pm 5.0$ & \\
\hline \multicolumn{3}{|c|}{$\alpha 7$ (formed by expression of $\alpha 7$ monomers) } \\
\hline (+)Epibatidine & $1.2 \pm 0.2$ & \\
\hline (-)Epibatidine & $1.1 \pm 0.2$ & \\
\hline Nicotine & $40 \pm 1.7$ & \\
\hline $\mathrm{ACh}$ & $79 \pm 37$ & \\
\hline \multicolumn{3}{|c|}{ Data from Moroni et al. (2006) } \\
\hline \multicolumn{3}{|c|}{ HS $\alpha 4 \beta 2$ (formed by $10: 1$ overexpression of $\beta 2: \alpha 4$ ) } \\
\hline Epibatidine & $0.02(0.01-0.03)$ & $0.6 \pm 0.02$ \\
\hline Nicotine & $1(0.8-1.3)$ & $0.28 \pm 0.01$ \\
\hline \multicolumn{3}{|c|}{$\operatorname{LS} \alpha 4 \beta 2$ (formed by $10: 1$ overexpression of $\alpha 4: \beta 2$ ) } \\
\hline Epibatidine & $1.3(0.4-4)$ & $2.2 \pm 0.02$ \\
\hline Nicotine & $34(23-50)$ & $0.62 \pm 0.03$ \\
\hline \multicolumn{3}{|c|}{ Data from Carbone et al. (2009) } \\
\hline \multicolumn{3}{|c|}{$\mathrm{HS} \alpha 4 \beta 2$ (formed by $10: 1$ overexpression of $\beta 2: \alpha 4$ ) } \\
\hline Epibatidine & $0.19(0.01-0.04)$ & $0.59 \pm 0.02$ \\
\hline $\mathrm{ACh}$ & $2.8(2.1-3.7)$ & $0.99 \pm 0.02$ \\
\hline \multicolumn{3}{|c|}{$\mathrm{HS} \alpha 4 \beta 2$ (formed with linked subunits) } \\
\hline Epibatidine & $0.16(0.1-0.03)$ & $0.60 \pm 0.014$ \\
\hline $\mathrm{ACh}$ & $2.37(2.1-2.7)$ & $1.02 \pm 0.01$ \\
\hline \multicolumn{3}{|c|}{$\mathrm{LS} \alpha 4 \beta 2$ (formed by $10: 1$ overexpression of $\alpha 4: \beta 2$ ) } \\
\hline Epibatidine & $2.3(0.8-7.0)$ & $2.4 \pm 0.26$ \\
\hline $\mathrm{ACh}$ & $88(76-94)$ & $1.1 \pm 0.04$ \\
\hline \multicolumn{3}{|c|}{$\mathrm{LS} \alpha 4 \beta 2$ (formed with linked subunits) } \\
\hline Epibatidine & $0.3(0.2-0.6)$ & $2.7 \pm 0.01$ \\
\hline $\mathrm{ACh}$ & $111(82-151)$ & $1.06 \pm 0.01$ \\
\hline
\end{tabular}

and Heinemann, 1991) and are of primary importance for $\mathrm{nAChR}$ function in the autonomic nervous system (David et al., 2010) and the adrenal gland (Sala et al., 2008), but in brain $\alpha 3$ expression is largely restricted to the medial habenula and the interpeduncular nucleus (Wada et al., 1989). The second major subtype of $n A C h R$ in brain is composed of homomeric assemblies of $\alpha 7$ subunits. Numerous functional and pharmacological properties

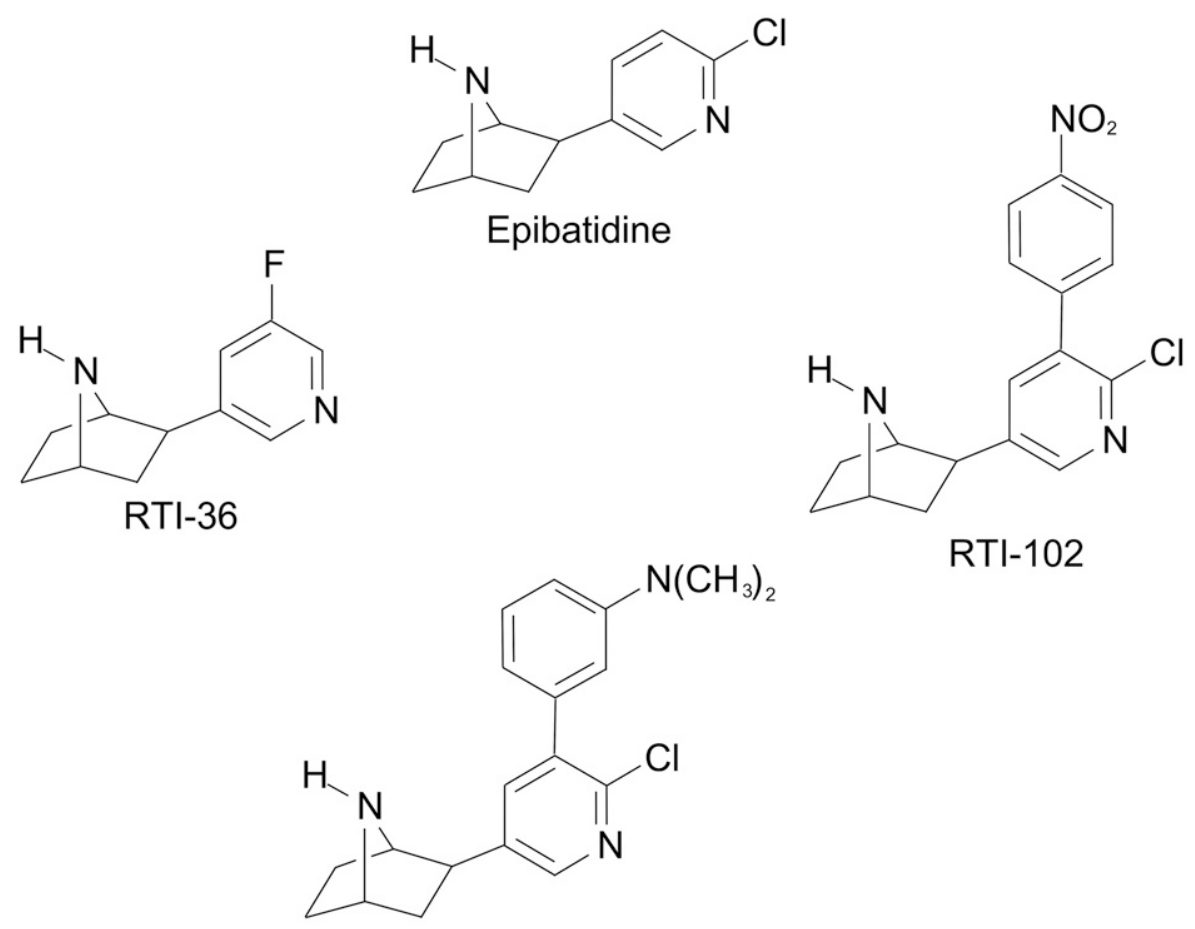

Fig. 1. Structures of epibatidine [2-(6-chloropyridin-3-yl)-7-azabicyclo[2.2.1]heptane] and test compounds RTI-36 (2'-fluorodeschloroepibatidine), RTI-76 [3'-(3"-dimethylaminophenyl)-epibatidine], and RTI-102 [2'-fluoro-3'-(4-nitrophenyl)deschloroepibatidine]. 
distinguish homomeric $\alpha 7$ receptors from the heteromeric receptors in brain (Papke and Lindstrom, 2020).

Efforts to understand both the acute and addictive effects of nicotine focus on $\beta 2$-containing receptors, especially those formed with $\alpha 4$ and, to a lesser degree, $\alpha 6$ subunits, especially in regard to addiction (Papke et al., 2020). Receptors with two $\alpha 4$ subunits and three $\beta 2$ subunits $(\alpha 4(2) \beta 2(3))$ are more sensitive to low concentrations of nicotine and more profoundly desensitized by high agonist concentrations than receptors with the reverse ratio $(\alpha 4(3) \beta 2(2))$. Of potential importance to nicotine addictions, it has been observed, at least in vitro, that chronic nicotine favors the expression of the high sensitivity (HS) $\alpha 4(2) \beta 2(3)$ form of the receptor (Srinivasan et al., 2011).

The frog toxin epibatidine is a very high affinity ligand for brain nAChR. It binds to the heteromeric nAChR in brain with an affinity 20-50 times higher than nicotine (Anderson et al., 1995; Ondachi et al., 2014). It is an efficacious activator of some nAChR subtypes (Table 1). It has been shown to be an extremely potent analgetic agent (Badio and Daly, 1994), and it has been used extensively as a scaffold to generate numerous novel and probative receptor ligands (Carroll, 2009). In this paper, we report the activity profile of three such derivatives (Fig. 1) on eight different $n A C h R$ subtypes, in all but one case controlling the precise receptor subunit composition through the use of linked subunit concatamers (Zhou et al., 2003; Kuryatov and Lindstrom, 2011) (Fig. 2). These compounds have all been previously characterized for receptor binding and their ability to mimic the in vivo systemic effects of injected nicotine regarding analgesia, hypothermia, and spontaneous activity (Table 2). However, since the relationship between these activities and their effects on specific nAChR subtypes is unknown, to some degree these experiments might be considered exploratory. Only one of these compounds, RTI-102, has been previously studied with electrophysiological methods, and despite its in vivo activity it was described as an antagonist (Abdrakhmanova et al., 2006). Interestingly, another highaffinity ligand for $\alpha 4 \beta 2$ receptors, sazetidine-A (Xiao et al., 2006), was initially described as an exclusively desensitizing agent but later revealed to be a selective activator for the HS $\alpha 4 \beta 2$ subtype (Zwart et al., 2008). Based on the early in vivo data on these compounds and the similarity between the initial characterizations of sazetidine-A and RTI-102 as antagonists, we were interested to determine if these compounds would have a selectivity for HS $\alpha 4 \beta 2$ and $\alpha 4 \beta 2$ receptors and receptors containing $\alpha 5$ and $\beta 3$ as structural subunits.

\section{Methods and Materials}

Commercial Reagents. ACh chloride, atropine, and other chemicals were purchased from Sigma-Aldrich Chemical Company (St. Louis, MO). Fresh ACh stock solutions were made in Ringer's solution each day of experimentation.

RTI Compounds. The synthesis and preliminary characterization of experimental compounds were previously described. RTI-36 ( $2^{\prime}$-fluorodeschloroepibatidine) was published as compound $3 \mathrm{a}$ in Carroll et al. (2005), RTI-76 [3'-(3"'-dimethylaminophenyl)-epibatidine] was published as compound $5 \mathrm{~m}$ in Carroll et al. (2010), and RTI102 [2'-fluoro-3'-(4-nitrophenyl)deschloro-epibatidine] was published as as compound 5g in Carroll et al. (2010).

Heterologous Expression of nAChRs in Xenopus laevis Oocytes. Human $\mathrm{nAChR}$ clones of monomeric subunits as well as the $\beta 2-6-\alpha 4$ and $\beta 3 \alpha 4 \beta 2 \alpha 6 \beta 2$ concatamers were obtained from Dr. J. Lindstrom (University of Pennsylvania, Philadelphia, PA). The $\beta 2$ 6- $\alpha 2$ concatamer was obtained from Edwin Johnson (Karolinska Institutet Sweden). The $\beta 2-6-\alpha 4$ concatamer construction is described in Zhou et al. (2003), and the $\beta 2-6-\alpha 2$ was made in similar fashion. Essentially, the $\mathrm{N}$ terminus is beta 2 with its signal sequence, yet they show that the assembled dimer places the alpha subunit in the primary position. The human resistance-to-cholinesterase 3 clone, obtained from Dr. M. Treinin (Hebrew University, Jerusalem, Israel), was coinjected with $\alpha 7$ to improve the level and speed of $\alpha 7$ receptor expression without affecting the pharmacological properties of the receptors (Halevi et al., 2003). Subsequent to linearization and purification of the plasmid cDNAs, cRNAs were prepared using the mMessage mMachine in vitro RNA transfection kit (Ambion, Austin, TX). The combinations of concatamer and monomeric clones used to generate receptors with defined subunit composition are illustrated in Figure 2. Alpha7:Ric3 was injected 2:1, and concatamer:monomer constructs were injected 1:1.

Oocytes were surgically removed from mature $X$. laevis frogs (Nasco, Ft. Atkinson, WI) and injected with appropriate nAChR subunit cRNAs as described previously (Papke and Stokes, 2010). Frogs were maintained in the Animal Care Service facility of the University of Florida, and all procedures were approved by the University of Florida Institutional Animal Care and Use Committee. In brief, the frog was first anesthetized for 15-20 minutes in $1.5 \mathrm{l}$ frog tank water containing $1 \mathrm{~g}$ of 3 -aminobenzoate methanesulfonate buffered with sodium bicarbonate. The harvested oocytes were treated with $1.25 \mathrm{mg} / \mathrm{ml}$ collagenase (Worthington Biochemicals, Freehold, $\mathrm{NJ})$ for 2 hours at room temperature in calcium-free Barth's solution $\left(88 \mathrm{mM} \mathrm{NaCl}, 1 \mathrm{mM} \mathrm{KCl}, 2.38 \mathrm{mM} \mathrm{NaHCO}_{3}, 0.82 \mathrm{mM} \mathrm{MgSO}_{4}, 15 \mathrm{mM}\right.$ HEPES, and $12 \mathrm{mg} / \mathrm{l}$ tetracycline, $\mathrm{pH}$ 7.6) to remove the follicular layer. Stage V oocytes were subsequently isolated and injected with 50

TABLE 2

Published data on RTI compounds

\begin{tabular}{|c|c|c|c|c|c|c|c|c|}
\hline \multirow{2}{*}{ Compound } & \multirow{2}{*}{$\begin{array}{c}\quad \alpha \beta \\
\text { Epibatidine } \\
\mathrm{Ki}, \mathrm{nM}\end{array}$} & \multirow{2}{*}{$\begin{array}{c}\alpha 7 \\
\text { MLA } \\
\text { Ki, nM }\end{array}$} & \multirow{2}{*}{$\begin{array}{c}\mathrm{ED}_{50} \\
\mathrm{mg} / \mathrm{kg} \\
\text { tail flick }\end{array}$} & \multirow{2}{*}{$\begin{array}{c}\mathrm{ED}_{50} \\
\mathrm{mg} / \mathrm{kg} \\
\text { hot plate }\end{array}$} & \multirow{2}{*}{$\begin{array}{c}\mathrm{ED}_{50} \\
\mathrm{mg} / \mathrm{kg} \\
\text { hypothermia }\end{array}$} & \multirow{2}{*}{$\begin{array}{c}\mathrm{ED}_{50} \\
\mathrm{mg} / \mathrm{kg} \\
\text { activity }\end{array}$} & \multicolumn{2}{|c|}{$\mathrm{AD}_{50}$} \\
\hline & & & & & & & $\begin{array}{c}\mu \mathrm{g} / \mathrm{kg} \\
\text { tail flick }\end{array}$ & $\begin{array}{c}\mu \mathrm{g} / \mathrm{kg} \\
\text { hot plate }\end{array}$ \\
\hline (+) epibatidine & $0.026 \pm 0.002$ & & .0061 & .0004 & .0004 & .001 & & \\
\hline (-) epibatidine & $0.018 \pm 0.001$ & & .0066 & & & & & \\
\hline Nicotine & $1.5 \pm 0.3$ & & 1.3 & & 0.65 & 1.0 & 0.5 & \\
\hline RTI-36 $6^{a \mathrm{a}}$ & $0.037 \pm 0.001$ & $>1000$ & 0.08 & 0.05 & 0.15 & 0.23 & 0.07 & $35 \% @ 20$ \\
\hline RTI-76 $6^{b \mathrm{~b}}$ & $0.009 \pm 0.001$ & $1100 \pm 157$ & 0\%@2 & 0\%@2 & 3.3 & 2.0 & 20 & 560 \\
\hline RTI- $102^{c c}$ & $0.009 \pm 0.001$ & & $5 \% @ 10$ & 10\%@10 & & 0.22 & 0.003 & 0.12 \\
\hline
\end{tabular}

${ }^{a}$ Carroll et al. (2005).

${ }^{b}$ Carroll et al. (2010).

${ }^{c}$ Carroll et al. (2004).

MLA, methyllycaconitine; $\mathrm{AD}_{50}$, anesthetic dose for $50 \%$ effect. 


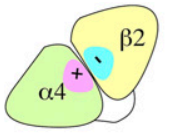

$\beta 2-6-\alpha 4$
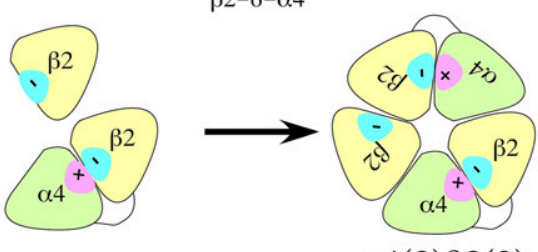

$\alpha 4(2) \beta 2(3)$
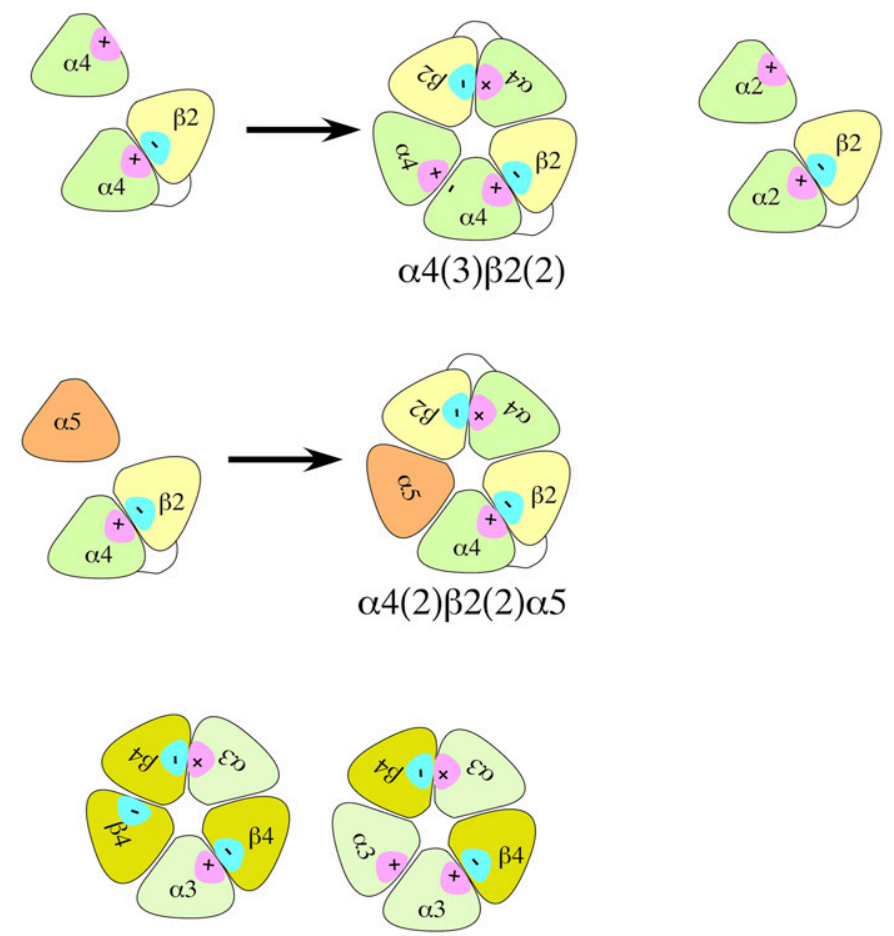

$\alpha 3 \beta 4$
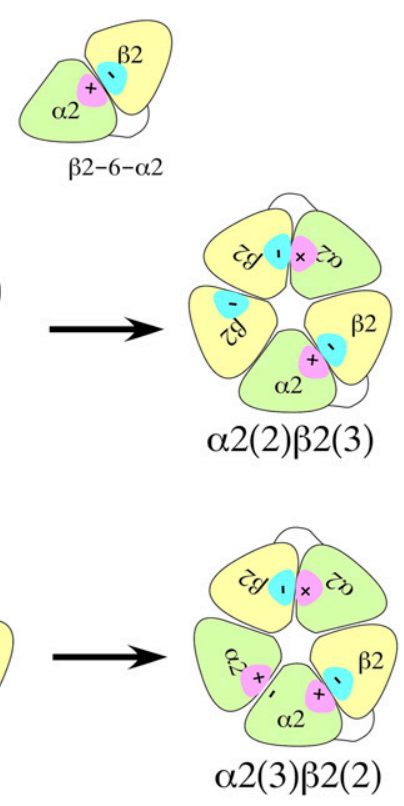

$\beta 2-6-\alpha 2$
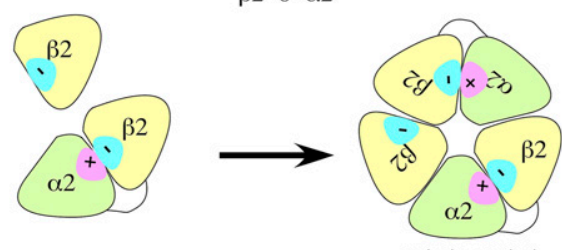

$\alpha 2(2) \beta 2(3)$

Fig. 2. nAChR subtypes studied formed from the coexpression of linked subunits and/or subunit monomers. To control the subunit composition of $\alpha 4 \beta 2$ and $\alpha 2 \beta 2$ receptors, we used concatamers of these subunits coexpressed with subunit monomers as indicated. The dimeric concatamers configure the $\alpha$ and $\beta$ subunits so that the primary surface of the orthosteric agonist binding site (+) on the $\alpha$ subunit faces the complementary surface $(-)$ on the $\beta$ subunit. Functional receptors assemble effectively with two concatamers and the subunit coexpressed as a monomer taking the fifth position as the accessory subunit (Zhou et al., 2003). A common form of $\alpha 6$-containing receptors also incorporates $\alpha 4, \beta 2$, and $\beta 3$ subunits (Gotti et al., 2010). We used a pentameric concatamer (Kuryatov and Lindstrom, 2011) to generate receptors with this subunit composition. Monomer $\alpha 3$ and $\beta 4$ subunits were coexpressed at equal ratios to most likely yield receptors with both $\alpha 3(3) \beta 4(2)$ and $\alpha 3(2) \beta 4(3)$ compositions. Functional $\alpha 7$ receptors are homomeric pentamers. nl of 5-20 ng nAChR subunit cRNA. Recordings were carried out 1-7 days after injection, when receptors were expressing well.

Two-Electrode Voltage Clamp Electrophysiology. Experiments were conducted at room temperature $\left(24^{\circ} \mathrm{C}\right)$ using OpusXpress 6000A (Molecular Devices, Union City, CA) (Papke and Stokes, 2010). Both the voltage and current electrodes were filled with $3 \mathrm{M} \mathrm{KCl}$. Oocytes were voltage-clamped at $-60 \mathrm{mV}$. The oocytes were bathperfused with Ringer's solution (115 mM NaCl, $2.5 \mathrm{mM} \mathrm{KCl}, 1.8 \mathrm{mM}$ $\mathrm{CaCl}_{2}, 10 \mathrm{mM}$ HEPES, and $1 \mu \mathrm{M}$ atropine, $\left.\mathrm{pH} 7.2\right)$ at $2 \mathrm{ml} / \mathrm{min}(\alpha 7)$ or at $4 \mathrm{ml} / \mathrm{min}$ (heteromeric). Drug applications were 12 seconds in duration followed by a 181-second washout period $(\alpha 7)$ or 6 seconds in duration followed by a 241 -second washout period (heteromeric). A typical recording for each set of oocytes constituted two initial control applications of $\mathrm{ACh}$, the application of an experimental compound, and then follow-up control applications of ACh to determine whether there was desensitization of subsequent ACh-evoked responses. The responses were calculated as both peak current amplitudes and net charge, as previously described (Papke and Porter Papke, 2002). The average holding current for the 30 seconds prior to drug applications was used for baseline adjustment of drug-evoked responses. The calculation of net charge encompassed a standard period of 120 seconds after the initiation of drug application. The average responses of the two initial ACh controls from each cell were used for normalization. For some concentration-response studies, increasing concentrations were tested on the same set of oocytes, but only if the $\mathrm{ACh}$ control responses between drug applications were stable (varying less than 25\%). Because applications of these compounds at high concentrations produced a degree of residual inhibition/desensitization, in many cases experiments were conducted with single drug applications to each set of cells, along with ACh controls. Data were initially normalized to ACh control responses from the same cells. For the receptor subtypes studied, the ACh control concentrations used were previously determined to give stable responses with repeated applications. They were $10 \mu \mathrm{M}$ ACh for $\alpha 4(2) \beta 2(3), \alpha 4(2) \beta 2(2) \alpha 5$, $\alpha 4 \beta 2 \alpha 6 \beta 2 \beta 3$, and $\alpha 2(2) \beta 2(3) ; 30 \mu \mathrm{M} \mathrm{ACh}$ for $\beta 3 \alpha 4 \beta 2 \alpha 6 \beta 2 ; 60 \mu \mathrm{M} \mathrm{ACh}$ for $\alpha 7$; and $100 \mu \mathrm{M}$ ACh for $\alpha 4(3) \beta 2(2), \alpha 2(3) \beta 2(2)$, and $\alpha 3 \beta 4$. For the determination of efficacy relative to $\mathrm{ACh}$, responses normalized to ACh controls were adjusted by the ratio of the ACh control responses to the ACh maxima previously determined (Papke and Porter Papke, 2002; Stokes and Papke, 2012; Papke et al., 2013) for the respective cell types.

Note that a large sample of the concentration-response data sets (15 drug/receptor combinations, with peak, net charge, and recovery data, 513 distributions total) were tested to determine if the data fit the model for normal distributions. Overall, based on the Shapiro-Wilk test conducted in Prizm (Version 8.4.2; GraphPad Software, San 
$\alpha 4(3) \beta 2(2)$

A

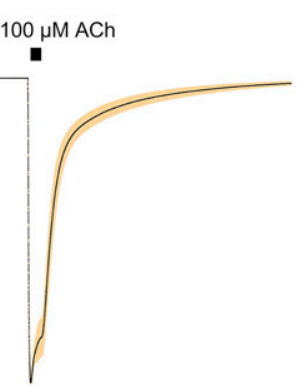

$1 \mu \mathrm{M} \mathrm{RTI}-36$

-
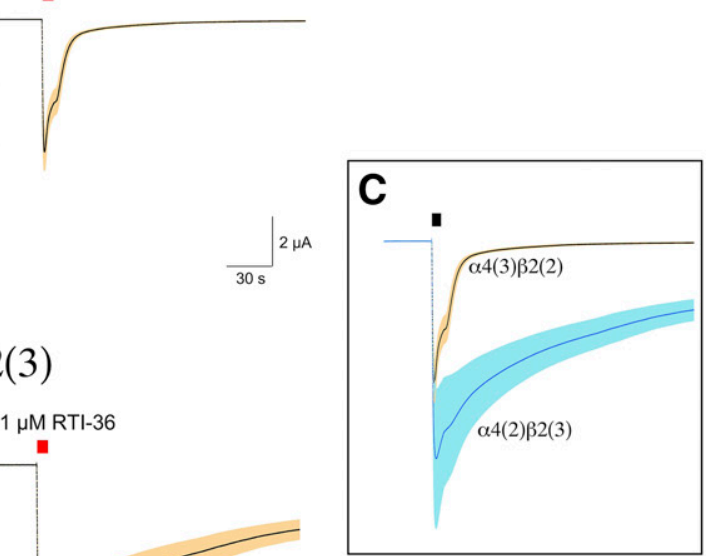

B

$\alpha 4(2) \beta 2(3)$
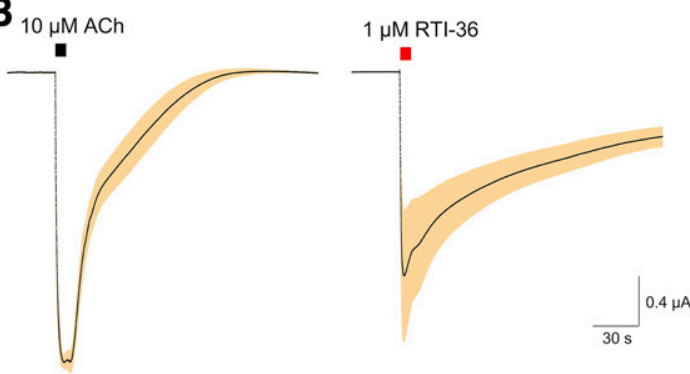

Fig. 3. Averaged raw data traces normalized to the control responses to ACh (see Methods and Materials). The S.E.M.s of the averaged normalized responses are represented by the tan colored areas. (A, B) Averaged responses $(n=7)$ of cells expressing LS [ $\alpha 4(3) \beta 2(2)]$ (A) and HS $[\alpha 4(2) \beta 2(3)]$ (B) receptors $(n=7)$ to $1 \mu$ M RTI-36 compared with ACh controls. (C) Kinetic comparison of the responses in (A and B). (D) Responses of cells expressing LS $[\alpha 4(3) \beta 2(2)]$ receptors $(n=6)$ to $10 \mu \mathrm{M}$ RTI-102 compared with ACh controls obtained prior to and after the application of RTI-102. (E) Responses of cells expressing HS $[\alpha 4(2) \beta 2(3)]$ receptors $(n=6)$ to 10 $\mu \mathrm{M}$ RTI-102 compared with ACh controls obtained prior to and after the application of RTI-102. Note that currents had not returned to baseline at the time of the follow-up ACh application, indicating persistent activation after the 6 -second application of RTI-102.
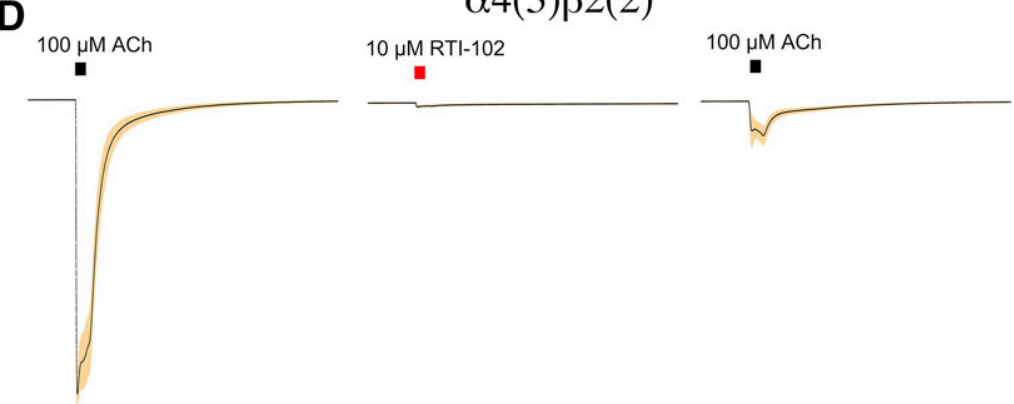

E

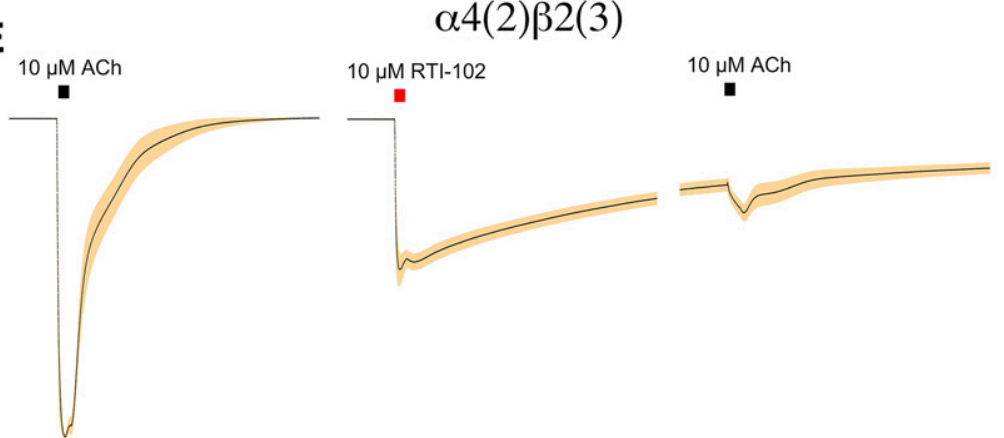

Diego, CA), $87.3 \%$ of the distributions passed the normality test (alpha $=0.05$ ).

Data were collected at $50 \mathrm{~Hz}$, filtered at $20 \mathrm{~Hz}(\alpha 7)$ or at $5 \mathrm{~Hz}$ (heteromeric), and analyzed by Clampfit 9.2 or 10.3 (Molecular Devices) and Excel (Microsoft, Redmond, WA). Every experiment began with eight cells (the capacity of the recording system); however, due to the nature of the experiments, not all cells remained viable through entire experiments, and some cells had large responses that could not be adequately voltage clamped. Therefore, $n$ varied from 5 to 8 (averaging 7.3). Experiments were discarded if $n$ fell below 5. Data are expressed as means \pm S.D. from at least five oocytes for each experiment (see figure legends or Supplemental Data for the $n$ values of each experiment) and plotted by Kaleidagraph 4.5.2 (Abelbeck Software, Reading, PA). Kaleidagraph 4.5.2 was also used to fit concentration-response functions to the Hill equation:

$$
\text { Response }=\frac{I_{\max }[\text { agonist }]^{n}}{[\text { agonist }]^{n}+\left(\mathrm{EC}_{50}\right)^{n}}
$$

The values for the curve fits were generated using the LevenbergMarquardt algorithm to obtain the best chi-square fit to the Hill equation using the Kaleidagraph 4.5.2 plotting program. The errors in the tables are the calculated S.E.s of the fit parameters based on the goodness of fit. The data plotted in the figures are the average 
TABLE 3

Curve fit values from plots of the averaged data (see Supplemental Data for plots and curve fits of data with all replicates) Errors estimated are based on the goodness of fit.

\begin{tabular}{|c|c|c|c|c|c|}
\hline & \multicolumn{2}{|c|}{ Peak currents } & \multicolumn{2}{|c|}{ Net charge } & \multirow{2}{*}{$\begin{array}{c}\text { Recovery } \\
\mathrm{IC}_{50} \\
\mu \mathrm{M} \\
\end{array}$} \\
\hline & $I_{\max }$ & $\begin{array}{c}\mathrm{EC}_{50} \\
\mu \mathrm{M}\end{array}$ & $I_{\max }$ & $\underset{\mu \mathrm{M}}{\mathrm{EC}_{50}}$ & \\
\hline \multicolumn{6}{|l|}{$\alpha 4(2) \beta 2(3)$} \\
\hline RTI-36 & $0.46 \pm 0.24$ & $0.15 \pm 0.04$ & $1.32 \pm 0.09$ & $.031 \pm 0.10$ & $0.11 \pm 0.03^{a}$ \\
\hline RTI-76 & $0.151 \pm 0.01$ & $0.09 \pm 0.01$ & $0.59 \pm 0.03$ & $0.12 \pm 0.02$ & $0.05 \pm 0.01^{a}$ \\
\hline RTI-102 & $0.46 \pm 0.013$ & $0.08 \pm 0.01$ & $1.57 \pm 0.10$ & $0.15 \pm 0.06$ & $0.106 \pm 0.04^{a \mathrm{a}}$ \\
\hline \multicolumn{6}{|l|}{$\alpha 4(3) \beta 2(2)$} \\
\hline RTI-36 & $0.49 \pm 0.035$ & $0.68 \pm 0.24$ & $0.95 \pm 0.40$ & $33 \pm 68$ & $6.0 \pm 1.6$ \\
\hline RTI-76 & $0.01 \pm 0.005$ & $4.0 \pm 11$ & $0.007 \pm 0.001$ & $0.014 \pm 0.011$ & $0.22 \pm 0.05$ \\
\hline RTI-102 & $0.006 \pm 0.001$ & $0.006 \pm 0.003$ & $0.02 \pm 0.001$ & $0.03 \pm 0.01$ & $1.02 \pm 0.12$ \\
\hline \multicolumn{6}{|l|}{$\alpha 2(2) \beta 2(3)$} \\
\hline RTI-36 & $0.28 \pm 0.02$ & $0.26 \pm 0.003$ & $0.94 \pm 0.19$ & $0.4 \pm 0.4$ & $1.1 \pm 0.6^{a}$ \\
\hline RTI-76 & $0.118 \pm 0.006$ & $0.032 \pm 0.008$ & $0.35 \pm 0.02$ & $0.11 \pm 0.04$ & $0.61 \pm 0.29^{a}$ \\
\hline RTI-102 & $0.13 \pm 0.008$ & $0.03 \pm 0.004$ & $0.42 \pm 0.05$ & $0.35 \pm 0.17$ & $1.96 \pm 0.16^{a}$ \\
\hline \multicolumn{6}{|l|}{$\alpha 2(3) \beta 2(2)$} \\
\hline RTI-36 & $0.62 \pm 0.04$ & $7.4 \pm 1.9$ & $0.97 \pm 0.07$ & $16.1 \pm 4.3$ & $48 \pm 22$ \\
\hline RTI-76 & $0.039 \pm 0.003$ & $0.28 \pm 0.16$ & $0.037 \pm 0.003$ & $0.6 \pm 0.2$ & $2.7 \pm 0.5$ \\
\hline RTI-102 & $0.024 \pm 0.003$ & $0.8 \pm 0.5$ & $0.041 \pm 0.007$ & $8.0 \pm 6.0$ & $5.8 \pm 1.3$ \\
\hline \multicolumn{6}{|l|}{$\alpha 4 \beta 25$} \\
\hline RTI-36 & $0.35 \pm 0.03$ & $0.034 \pm 0.018$ & $1.24 \pm 0.05$ & $0.28 \pm 0.06$ & $1.78 \pm 0.29^{a}$ \\
\hline RTI-76 & $0.033 \pm 0.002$ & $0.05 \pm 0.01$ & $0.13 \pm 0.01$ & $0.21 \pm 0.05$ & $0.30 \pm 0.03$ \\
\hline RTI-102 & $0.06 \pm 0.005$ & $0.014 \pm 0.007$ & $0.28 \pm 0.02$ & $0.59 \pm 0.27$ & $1.3 \pm 0.18$ \\
\hline \multicolumn{6}{|c|}{$\beta 3 \alpha 4 \beta 2 \alpha 6 \beta 2$} \\
\hline RTI-36 & $0.36 \pm 0.015$ & $0.008 \pm 0.002$ & $0.84 \pm 0.05$ & $0.21 \pm 0.09$ & $0.54 \pm 0.09^{a}$ \\
\hline RTI-76 & $0.023 \pm 0.002$ & $0.004 \pm 0.001$ & $0.08 \pm 0.01$ & $0.08 \pm 0.05$ & $0.45 \pm 0.06$ \\
\hline RTI-102 & $0.042 \pm 0.01$ & $0.013 \pm 0.002$ & $0.16 \pm 0.02$ & $0.87 \pm 0.43$ & $1.5 \pm 0.39$ \\
\hline \multicolumn{6}{|l|}{$\alpha 7^{n 11-102}$} \\
\hline RTI-36 & $1.92 \pm 0.10$ & $3.5 \pm 0.6$ & $0.8 \pm 0.08$ & $1.1 \pm 0.3$ & $90 \pm 25$ \\
\hline RTI-76 & $1.04 \pm 0.08$ & $22 \pm 2$ & $0.26 \pm 0.01$ & $4.9 \pm 0.4$ & $168 \pm 26$ \\
\hline RTI-102 & $0.45 \pm 0.15$ & $123 \pm 9.3$ & $0.11 \pm 0.003$ & $59.8 \pm 3.9$ & $1600 \pm 1750$ \\
\hline \multicolumn{6}{|l|}{$\alpha 3 \beta 4$} \\
\hline RTI-36 & $3.65 \pm 0.31$ & $1.7 \pm 0.6$ & $6.69 \pm 0.20$ & $4.07 \pm 0.4$ & NA \\
\hline RTI-76 & $0.88 \pm 0.07$ & $0.47 \pm 0.18$ & $0.39 \pm 0.06$ & NA & $22 \pm 3.5$ \\
\hline RTI-102 & $1.40 \pm 0.06$ & $0.69 \pm 0.1$ & $3.12 \pm 0.27$ & $4.7 \pm 1.6$ & NA \\
\hline
\end{tabular}

${ }^{a}$ Significant baseline jumps.

NA, data not available.

response ( \pm S.D.), and the curve fits in the figures are fits to those averages. As an alternative approach that would allow the fitting procedure to respond to the variability of the data at each concentration, we also plotted the concentration-response data with every replicate (Supplemental Figs. 1-16) and generated curve fits to those data. Supplemental Table 1 includes the chi-square and $R$ values for those fits. Note that the curve fit parameters were essentially identical for the two approaches (Supplemental Table 2), except for a few cases with the off-target $\alpha 7$ and $\alpha 3 \beta 4$ receptors where the replicate data could not be adequately fit to the Hill equation.

To avoid the potential bias that might come from the selection of "representative" raw data, in some figures we display multicell averages of the raw data for comparisons of responses. The averages of normalized raw data were calculated using an Excel (Microsoft) template for each of the 10,500 points in each of the 210-second traces (acquired at $50 \mathrm{~Hz}$ ). After subtraction of the basal holding current, data from each cell, including the ACh controls, were normalized by dividing each point by the peak of the ACh control from the same cell. The normalized data were then averaged and S.E.M. for the multicell averages calculated on a point-by-point basis. The dark lines represent the average normalized currents and the shaded areas the range of the S.E.M. Scale bars in the figures of averaged traces reflect the scaling factor relative to the average peak current amplitude of the ACh controls used for the normalization procedures. These plots are effectively augmented versions of typical bar plots of peak currents that additionally illustrate the differences in net charge, the kinetics of the responses, and the variability throughout the entire time course of the responses.

Statistical analyses of pairwise data sets in Figure 3C were conducted based on two-tailed $t$ test comparisons of the normalized net-charge data. Data in other figures may be taken to illuminate the differing activity of these compounds revealed by these exploratory studies.

\section{Results}

Effects of $\alpha 4: \beta 2$ Subunit Stoichiometry on Voltage-Clamp Currents. By coexpressing the linked $\beta 2-6-\alpha 4$ subunits with either $\alpha 4$ or $\beta 2$ monomers (Zhou et al., 2003) we obtained $\alpha 4 \beta 2$ receptors with either $\alpha 4(3) \beta(2)$ or $\alpha 4(2) \beta 2(3)$ composition (Fig. 2). Averaged raw data traces are shown in Figure 3. Prior to averaging, each cell's response was normalized to the peak current of the ACh control responses obtained from the same cells. Note that the $\alpha 4(3) \beta(2)$ and $\alpha 4(2) \beta 2(3)$ receptors have previously been identified as having either low sensitivity (LS) or HS to agonists, respectively (Zhou et al., 2003), and so the ACh control concentrations were 100 and $10 \mu \mathrm{M}$ for the $\alpha 4(3) \beta(2)$ and $\alpha 4(2) \beta 2(3)$ receptors, respectively. One striking difference was that the responses of the HS receptors to the RTI epibatidine derivatives were protracted well beyond the period of drug washout compared with the LS receptor responses. This effect is shown for the responses to $1 \mu \mathrm{M}$ RTI-36 (Fig. 3, A-C). These differences are reflected in the comparisons of peak currents and net charge over the 120second intervals after the beginning of the RTI-36 applications (see Methods and Materials). For the LS $\alpha 4(3) \beta(2)$ 
responses, compared with the ACh controls, responses calculated as net charge were only $67 \%$ as large as the peak currents, whereas for the HS $\alpha 4(2) \beta(3)$ responses, the normalized net charge values were $267 \%$ compared with the peak currents. To systematically study these differences, we conducted concentration-response analyses on both peak currents and net charge measurements in subsequent figures and Table 3.

The $\alpha 4 \beta 2$ subunit composition also had a large effect on the efficacy of RTI-102 in particular. As shown, the LS $\alpha 4(3) \beta(2)$ receptors were virtually unresponsive to $10 \mu \mathrm{M}$ RTI-102 (Fig. 3D), whereas the HS $\alpha 4(2) \beta(3)$ receptors gave large and prolonged responses (Fig. 3E).

In addition to measuring the evoked responses, we measured the desensitization of subsequent ACh-evoked responses (calculated as "recovery" in the concentration-response figures). Note that although $10 \mu \mathrm{M}$ RTI-102 did not activate substantial currents in $\operatorname{LS} \alpha 4(3) \beta(2)$ receptors, it did strongly inhibit the response evoked by $100 \mu \mathrm{M}$ ACh when it was applied 280 seconds after $10 \mu \mathrm{M}$ RTI-102 (Fig. 3D). Note also that $10 \mu \mathrm{M}$ ACh produced only a comparably small response when applied to the HS $\alpha 4(2) \beta(3)$ receptors after $10 \mu \mathrm{M}$ RTI-102; however, this was on top of an elevated baseline due to the protracted response to the $10 \mu \mathrm{M}$ RTI102. Such elevated baselines were observed with several receptor subtype/drug combinations and are discussed in later sections. In the case of the $\operatorname{HS} \alpha 4(2) \beta(3)$ receptors, all three of the test compounds gave protracted responses of varying duration (Fig. 4), with the RTI-36 responses showing the slowest decay.

The complete concentration-response studies for all three compounds on both LS and HS $\alpha 4 \beta 2$ receptors are shown in Figure 5, and the curve fit values are given in Table 3. All three compounds were relatively efficacious for HS $\alpha 4(2) \beta(3)$ receptors (RTI-36 $\approx$ RTI-102 > RTI-76), and for all three compounds the net charge $I_{\max }$ was greater than the $I_{\max }$ for peak currents due to the protracted nature of the responses as illustrated in Figure 3. The only one of the compounds with high efficacy for $\operatorname{LS} \alpha 4(3) \beta(2)$ receptors was RTI-36. Note that, consistent with Figure 3, the average net-charge and peakcurrent values for RTI-36 were similar across the entire range of concentrations. However, the RTI-36 net-charge data were not well fit by the Hill equation, as evidenced by the large error estimate of the $\mathrm{EC}_{50}$.

All of the compounds were effective at reducing subsequent ACh control responses (Fig. 5), although as noted above, for the HS $\alpha 4(2) \beta(3)$ receptors the subsequent ACh response rode on top of the sustained responses that had not returned to the original baselines (see Fig. 3). Interestingly, the least effective activator, RTI-76, was the most potent desensitizer.

Responses of $\alpha 2 \beta 2$ Receptors to the Epibatidine Analogs. Although $\alpha 4$-containing receptors are the most abundant high-affinity $\mathrm{nAChR}$ in rodent brain, in primates there are additional high-affinity receptors containing $\alpha 2$ subunits (Han et al., 2000, 2003). By using a $\beta 2-6-\alpha 2$ concatamer similar to the $\beta 2-6-\alpha 4$ used to generate the HS and LS $\alpha 4 \beta 2$ subtypes, $\alpha 2 \beta 2$ receptors with specific subunit composition were also generated (Fig. 2). We have previously shown that these $\alpha 2(3) \beta(2)$ and $\alpha 2(2) \beta 2(3)$ receptors have pharmacological profiles similar to the $\alpha 4 \beta 2$ counterparts in regard to $\mathrm{ACh}$, nicotine, and the HS subtype-selective agonist TC-2559 (Papke et al., 2013).

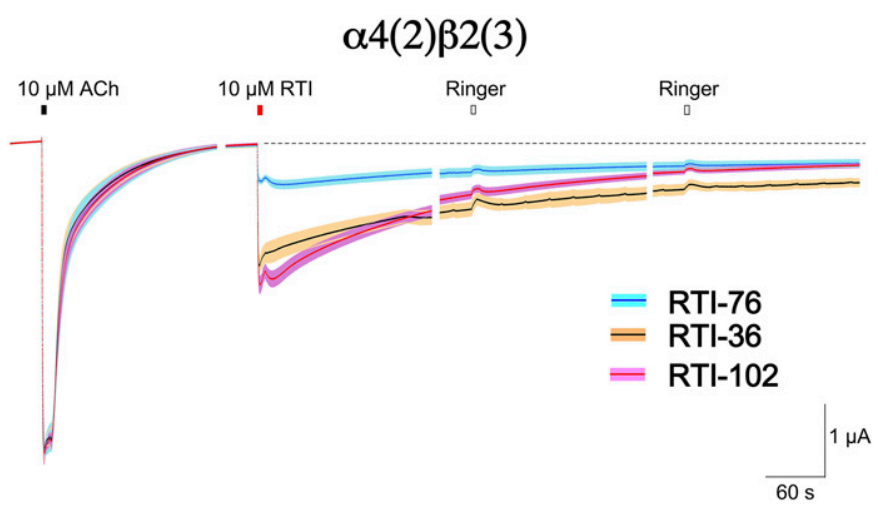

Fig. 4. Responses of $\alpha 4(2) \beta 2(3)$ receptors to $10 \mu \mathrm{M}$ applications of the test compounds. Control responses to $10 \mu \mathrm{M}$ ACh were obtained from cells expressing $\alpha 4(2) \beta 2(3)$ receptors followed by 6 -second applications of either RTI-36 $(n=5)$, RTI-76 $(n=5)$, or RTI-102 $(n=6)$ and then two follow-up applications of Ringer's solution from the drug application system, basically switching from bulk flow to acute focused 6-second delivery of the same solution. All three compounds evoked responses that failed to return to baseline after 12 minutes of washout. The switch from bulk flow to pipette delivery produced small perturbations in the persisting currents, which may represent changes in the dynamics of drug unbinding and rebinding during sustained responses, perhaps suggesting that the oocyte membrane itself functions as a reservoir for residual drug (Papke et al., 1997).

In most regards, the HS and $\operatorname{LS} \alpha 2 \beta 2$ receptors had similar responses to the epibatidine derivatives as the HS and LS $\alpha 4 \beta 2$ subtypes (Fig. 6; Table 3). Only RTI-36 had much efficacy for activating the LS $\alpha 2 \beta 2$ receptors, and all three produced protracted responses in the HS $\alpha 2 \beta 2$ receptors, as evidenced by the increased net charge compared with peak current $I_{\text {max }}$ values and the consistent increase in baselines after application of the compounds at high concentrations. The most striking difference in the profiles was reduced efficacy of RTI-102 for the HS $\alpha 2 \beta 2$ receptors compared with the HS $\alpha 4 \beta 2$ receptors. The $\mathrm{IC}_{50}$ values (Table 3 ) were overall higher for the $\alpha 2 \beta 2$ receptors than for the $\alpha 4 \beta 2$ receptors, but again RTI-76 was the most potent desensitizer of the test compounds.

Responses of Alternative $\alpha 4 \beta 2$-Containing Receptors to the Epibatidine Analogs. Among the nAChR subtypes associated with nicotine self-administration are subtypes containing either $\alpha 5$ (Grady et al., 2010; Jackson et al., 2010; Picciotto and Kenny, 2013) or $\alpha 6$ subunits (Jackson et al., 2009; Liu et al., 2012; Sanjakdar et al., 2015). Although these subunits may incorporate into multiple receptor subtypes, at least some important forms also contain $\alpha 4$ and $\beta 2$ (Kuryatov et al., 2008; Drenan et al., 2010; Kuryatov and Lindstrom, 2011; Sala et al., 2013). The coexpression of $\alpha 5$ with the $\beta 2-$ $6-\alpha 4$ (Fig. 2) yields a high-sensitivity receptor in some ways similar to $\alpha 4(2) \beta 2(3)$ receptors (Zhou et al., 2003; Papke et al., 2013). Although $\alpha 6$-containing receptors are acknowledged as an important target for understanding nicotine's effects in the brain, they were not an easy receptor to get to function in a heterologous system prior to the development of a pentameric $\beta 3 \alpha 4 \beta 2 \alpha 6 \beta 2$ concatamer (Kuryatov and Lindstrom, 2011). This construct incorporates $\beta 3$ as the structural subunit and has ACh binding sites at the $\alpha 4 \beta 2$ and $\alpha 6 \beta 2$ interfaces (Fig. 2).

Of the three test compounds, RTI-36 was the most efficacious agonist for both $\alpha 4(2) \beta 2(2) \alpha 5$ and $\beta 3 \alpha 4 \beta 2 \alpha 6 \beta 2$ receptors, with net-charge responses having much higher $\mathrm{I}_{\max }$ values than the peak-current responses, and baseline shifts 
Activation
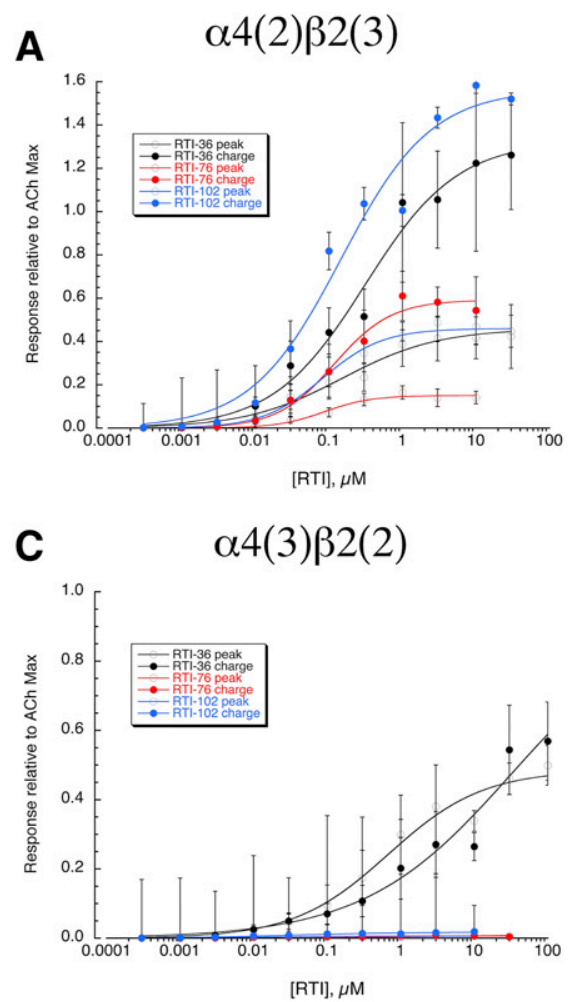

Recovery

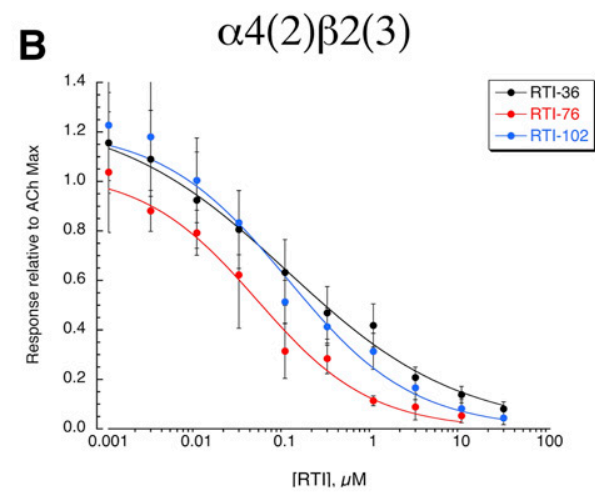

D

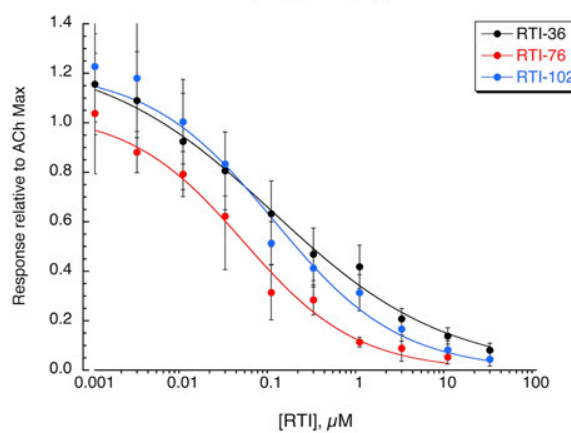

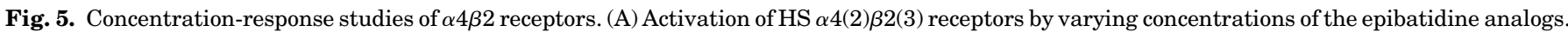

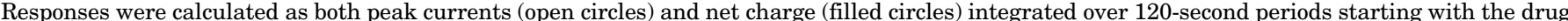

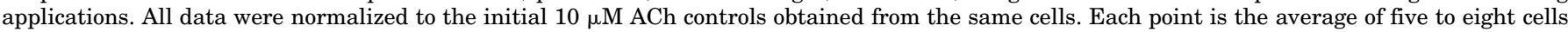

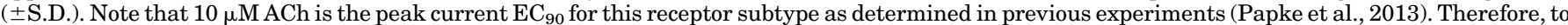

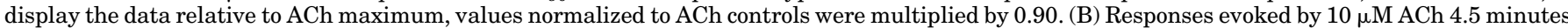

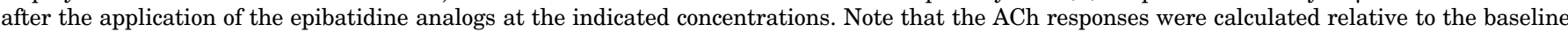

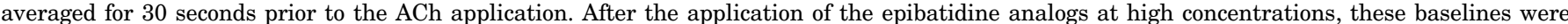

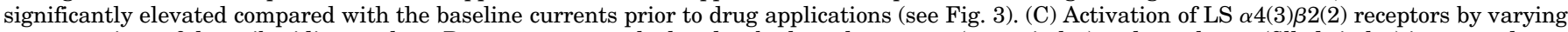

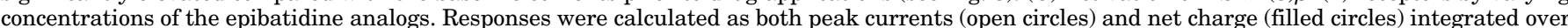

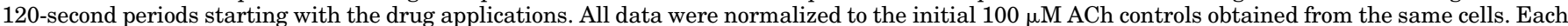

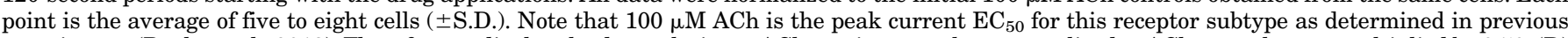

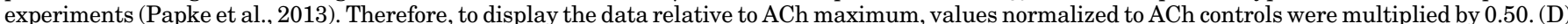

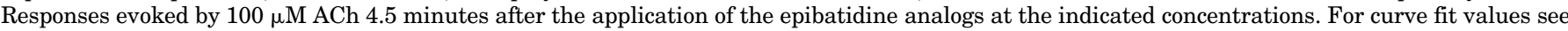

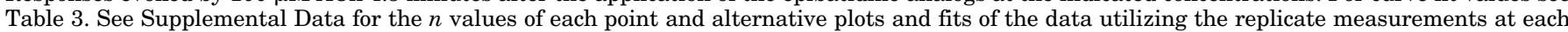
concentration.

consistent with protracted responses like those of the HS $\alpha 4 \beta 2$ and HS $\alpha 2 \beta 2$ receptors (Fig. 7; Table 3). Although a relatively weak agonist, RTI-76 was a potent desensitizer for both of these receptors.

The averaged raw data responses of $\beta 3 \alpha 4 \beta 2 \alpha 6 \beta 2$ receptors to $10 \mu \mathrm{M}$ RTI-36 are shown in Fig. 8. Prior to averaging, each single cell's response was normalized the control $30 \mu \mathrm{M}$ ACh responses from the same cell. At the time when the follow-up ACh application was made, 4.5 minutes after the 6 -second application of RTI-36, the steady-state baseline current was on average $740 \mathrm{nA}, 16 \%$ the amplitude of the initial $\mathrm{ACh}$ control. The estimated net charge during the post-RTI-36 control period (the rightmost trace in Fig. 7) was $106 \% \pm$ $7 \%$ the net charge of the initial ACh control responses.

A summary of all the receptors that showed significant increases in baseline currents prior to the post control ACh applications is shown in Figure 9. Data represent the current 4.5 minutes after drug application normalized to the peak currents of the initial ACh controls. For all three drugs the most sensitive receptors were the HS $\alpha 4 \beta 2$ and HS $\alpha 2 \beta 2$ subtypes. Smaller shifts were observed for $\alpha 4(2) \beta 2(2) \alpha 5$ and $\beta 3 \alpha 4 \beta 2 \alpha 6 \beta 2$ receptors, although for RTI-36, shifts for these receptors were quite substantial (see Fig. 7).

Responses of Alternative nAChR Lacking $\alpha 4$ and $\beta 2$ Subunits to the Epibatidine Analogs. Homomeric $\alpha 7$ receptors, the second major type of $\mathrm{nAChR}$ in brain, which do not bind nicotine or ACh with high affinity, have many features that distinguish them from heteromeric nAChR (Papke and Lindstrom, 2020). The unique rapid concentrationdependent desensitization of $\alpha 7$ receptors makes the measurement of peak currents an almost meaningless measure of the concentration dependence of receptor function, since high concentrations of agonist stimulate peak currents prior to complete application of the drug solutions. This limitation is largely overcome by relying on net charge as a measure of $\alpha 7$ responses (Papke and Porter Papke, 2002; Papke, 2006, 2010, 2014). As with the $\beta 2$-containing receptors, we saw that RTI36 was the most efficacious of the three epibatidine derivatives tested and the only one that might be classified as a full agonist (Fig. 10A; Table 3). The potency of RTI-36 for $\alpha 7$ 

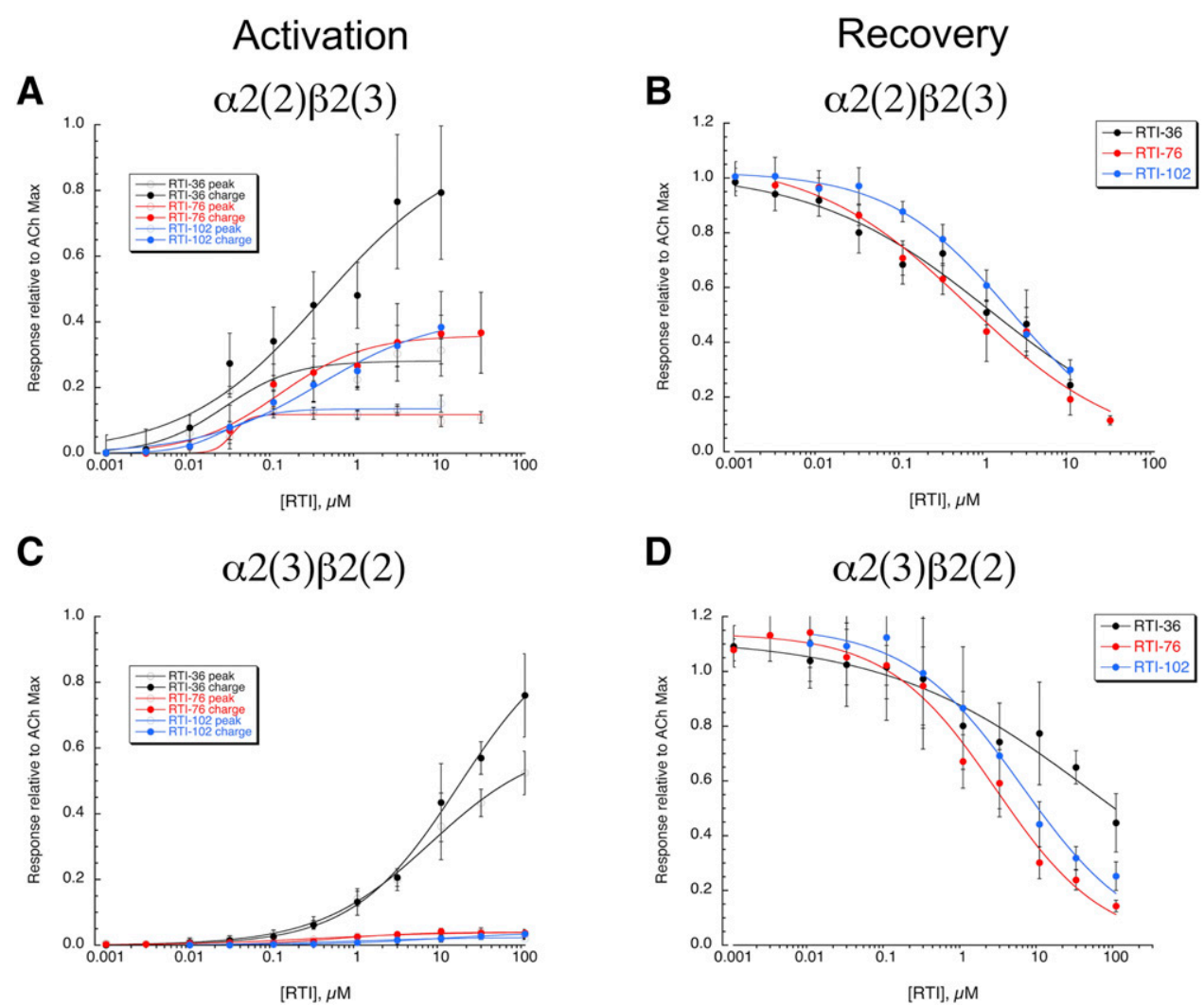

Fig. 6. Concentration-response studies of $\alpha 2 \beta 2$ receptors. (A) Activation of $\operatorname{HS} \alpha 2(2) \beta 2(3)$ receptors by varying concentrations of the epibatidine analogs. Responses were calculated as both peak currents (open circles) and net charge (filled circles) integrated over 120 -second periods starting with the drug applications. All data were normalized to the initial $10 \mu \mathrm{M}$ ACh controls obtained from the same cells. Each point is the average of five to eight cells ( \pm S.D.). Note that $10 \mu \mathrm{M}$ ACh is the peak current $\mathrm{EC}_{82}$ for this receptor subtype as determined in previous experiments (Papke et al., 2013). Therefore, to display the data relative to ACh maximum, values normalized to ACh controls were multiplied by 0.82 . (B) Responses evoked by $10 \mu \mathrm{M}$ ACh 4.5 minutes after the application of the epibatidine analogs at the indicated concentrations. Note that the ACh responses were calculated relative to the baseline averaged for 30 seconds prior to the ACh application. After the application of the epibatidine analogs at high concentrations, these baselines were significantly elevated compared with the baseline currents prior to drug applications (see Fig. 3). (C) Activation of LS $\alpha 2(3) \beta 2(2)$ receptors by varying concentrations of the epibatidine analogs. Responses were calculated as both peak currents (open circles) and net charge (filled circles) integrated over 120 -second periods starting with the drug applications. All data were normalized to the initial $100 \mu \mathrm{M}$ ACh controls obtained from the same cells. Each point is the average of five to eight cells ( \pm S.D.). Note that $100 \mu \mathrm{M}$ ACh is the peak current $\mathrm{EC}_{34}$ for this receptor subtype as determined in previous experiments (Papke et al., 2013). Therefore, to display the data relative to ACh maximum, values normalized to ACh controls were multiplied by 0.34. (D) Responses evoked by $100 \mu \mathrm{M}$ ACh 4.5 minutes after the application of the epibatidine analogs at the indicated concentrations. For curve fit values see Table 3. See Supplemental Data for the $n$ values of each point and alternative plots and fits of the data utilizing the replicate measurements at each concentration.

receptors was also relatively high, ranking between the potency for HS and LS subtypes of the $\alpha 4$ - and $\alpha 2$-containing receptors. However, the $\alpha 7$ responses to RTI-36 were not protracted, and RTI- 36 was not a potent desensitizer. The $\mathrm{IC}_{50}$ was 90 -fold higher than the $\mathrm{EC}_{50}$ for net charge (Table 3). Note that the differing curve fit values for $\alpha 7$ peak currents and net charge were as expected for this receptor and represent the artifact associated with $\alpha 7$ desensitization mentioned above (Papke and Porter Papke, 2002). We observed partial agonist activity for RTI-76 and to a lesser degree RTI-102, although they were not very potent and produced relatively little desensitization of the postapplication ACh controls.

As noted in the introduction, the $\alpha 3$ subunit has a relatively restricted pattern of expression in the brain but is essential for synaptic function in the autonomic nervous system, where it can coassemble with $\beta 4$ subunits. Since all $\mathrm{nAChR}$ subunits vary greatly in their intracellular domain sequences (Stokes et al., 2015), the most cogent basis for sequence comparisons of functional domains evaluates just the extracellular and transmembrane portions of the receptors, which are responsible for ligand binding and ion conduction, respectively.
In these domains $\alpha 4$ and $\alpha 2$ share $82.98 \%$ sequence identity. In contrast, $\alpha 4$ and $\alpha 3$ have only $69.44 \%$ sequence identity in these domains. Consistent with its activity on other receptors, we found RTI- 36 to be the most efficacious analog of the three tested on $\alpha 3 \beta 4$ (Fig. 10). The $\mathrm{I}_{\max }$ for RTI-36 peak currents was $9.4 \pm 0.8$ times the peak currents of the ACh controls. As the ACh control concentration was determined in previous experiments to be the $\mathrm{EC}_{39}$, the estimated $\mathrm{I}_{\max }$ for RTI-36 peak currents would be 3.65 -fold larger than the ACh $\mathrm{I}_{\max }$. RTI-76 and RTI-102 both effectively activated $\alpha 3 \beta 4$, but only in the case of RTI-36 were currents protracted, and only RTI76 was an effective desensitizer of these receptors.

\section{Discussion}

Epibatidine has been an important inspiration to nicotinic drug development and a valuable tool for the characterization of nicotinic receptor binding sites (Houghtling et al., 1995; Carroll, 2009). Like epibatidine, the three analogs used in the present study show high affinity for heteromeric $\mathrm{nAChR}$ and very low affinity for $\alpha 7$-type receptors (Table 2). However, they 
Activation
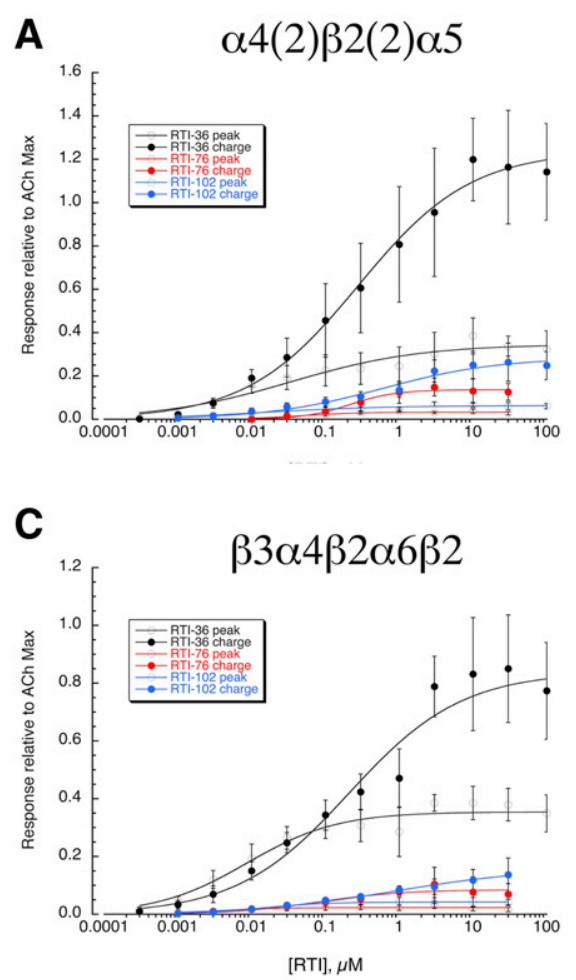

Recovery

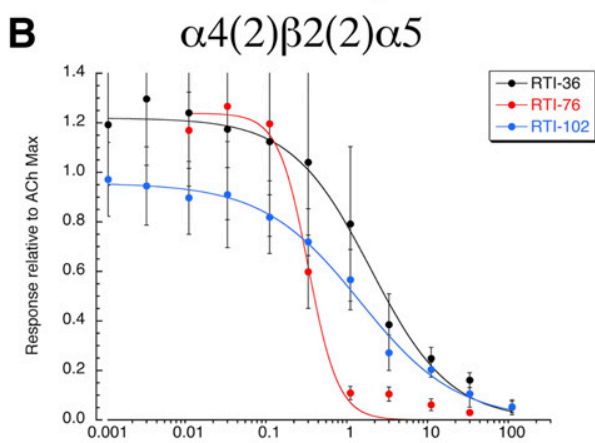

D

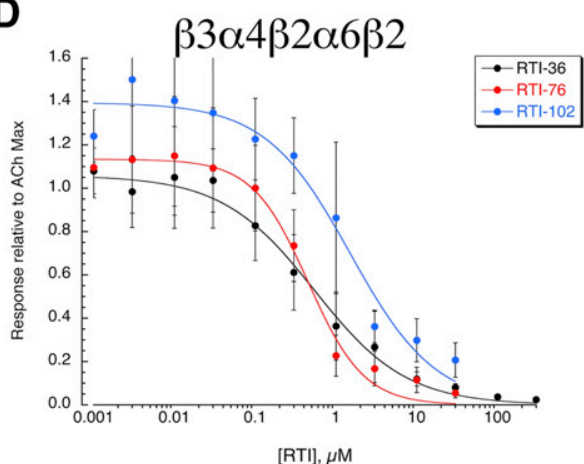

Fig. 7. Concentration-response studies of other $\alpha 4 \beta 2$-containing receptors. (A) Activation of $\alpha 4 \beta 2 \alpha 5$ receptors by varying concentration of the epibatidine analogs. Responses were calculated as both peak currents (open circles) and net charge (filled circles) integrated over 120 -second periods starting with the drug applications. All data were normalized to the initial $10 \mu \mathrm{M}$ ACh controls obtained from the same cells. Each point is the average of five to eight cells ( \pm S.D.). Note that $10 \mu \mathrm{M}$ ACh is the peak current $\mathrm{EC}_{69}$ for this receptor subtype as determined in previous experiments (Papke et al., 2013). Therefore, to display the data relative to ACh maximum, values normalized to ACh controls were multiplied by 0.69 . (B) Responses evoked by 10 $\mu \mathrm{M}$ ACh 4.5 minutes after the application of the epibatidine analogs at the indicated concentrations. Note that the ACh responses were calculated relative to the baseline averaged for 30 seconds prior to the ACh application. After the application of the epibatidine analogs at high concentrations, in some cases these baselines were significantly elevated compared with the baseline currents prior to drug applications. (C) Activation of $\beta 3 \alpha 4 \beta 2 \alpha 6 \beta 2$ receptors by varying concentration of the epibatidine analogs. Responses were calculated as both peak currents (open circles) and net charge (filled circles) integrated over 120-second periods starting with the drug applications. All data were normalized to the initial $30 \mu \mathrm{M}$ ACh controls obtained from the same cells. Each point is the average of five to eight cells ( \pm S.D.). Note that $30 \mu \mathrm{M}$ ACh is the peak current $\mathrm{EC}_{76}$ for this receptor subtype as determined in previous experiments (Papke et al., 2013). Therefore, to display the data relative to ACh maximum, values normalized to ACh controls were multiplied by 0.76. (D) Responses evoked by $30 \mu \mathrm{M}$ ACh 4.5 minutes after the application of the epibatidine analogs at the indicated concentrations. For curve fit values see Table 3. See Supplemental Data for the $n$ values of each point and alternative plots and fits of the data utilizing the replicate measurements at each concentration.

were found to have significantly less activity than epibatidine in measurements of acute analgetic effects. The retention of high-affinity binding, along with reduced activity in at least

\section{$\beta 3 \alpha 4 \beta 2 \alpha 6 \beta 2$}

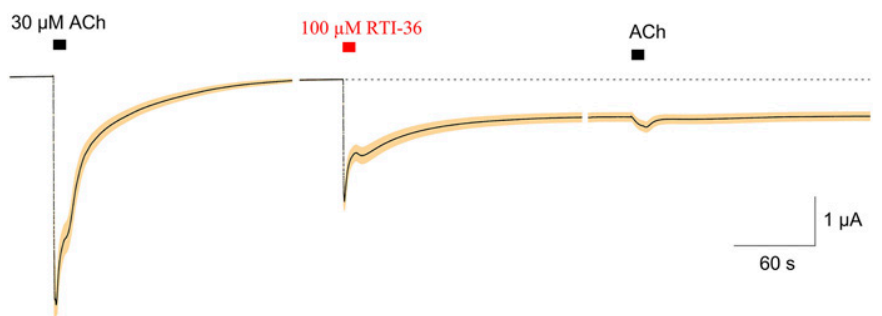

Fig. 8. Protracted currents and baselines with $\beta 3 \alpha 4 \beta 2 \alpha 6 \beta 2$ receptors stimulated by $100 \mu \mathrm{M}$ RTI-36. Averaged raw data traces $(n=8)$, normalized to the control responses to ACh shown (see Methods and Materials). The S.E.M.s of the averaged normalized responses are represented by the tan colored areas. Note that currents had not returned to baseline at time of the second ACh application, indicating persistent activation after the 6-second application of RTI-36. some functional assays, could be consistent with the conversion of epibatidine from an agonist to a high-affinity antagonist due to the structural differences. However, our current appreciation of the fact that the binding sites present in crude preparations of brain membranes represent a wide variety nAChR subtypes encouraged us to determine the activity profiles of these compounds on a range of structurally defined receptor subunits.

Previously, RT1-102 was characterized as an antagonist using cells expressing $\alpha 4 \beta 2 \mathrm{nAChR}$ (Abdrakhmanova et al., 2006). Our data indicate that this would be consistent with a preferential expression of the $\operatorname{LS} \alpha 4(3) \beta 2(2)$ subtype in those cells, since RT1-102 was an efficacious agonist for the alternative HS $\alpha 4(2) \beta 2(3)$ receptor subtype. RTI-102 then joins sazetidine-A and TC-2559 (Moroni et al., 2006) as an HS $\alpha 4(2) \beta 2(3)$ selective agonist.

Our observations regarding the crucial importance of the precise subunit composition on the activity of these compounds for heteromeric $\alpha 4$-containing (and $\alpha 2$-containing) receptors highlights the importance of better identifying the detailed features of brain receptors in vivo. In animals (or 


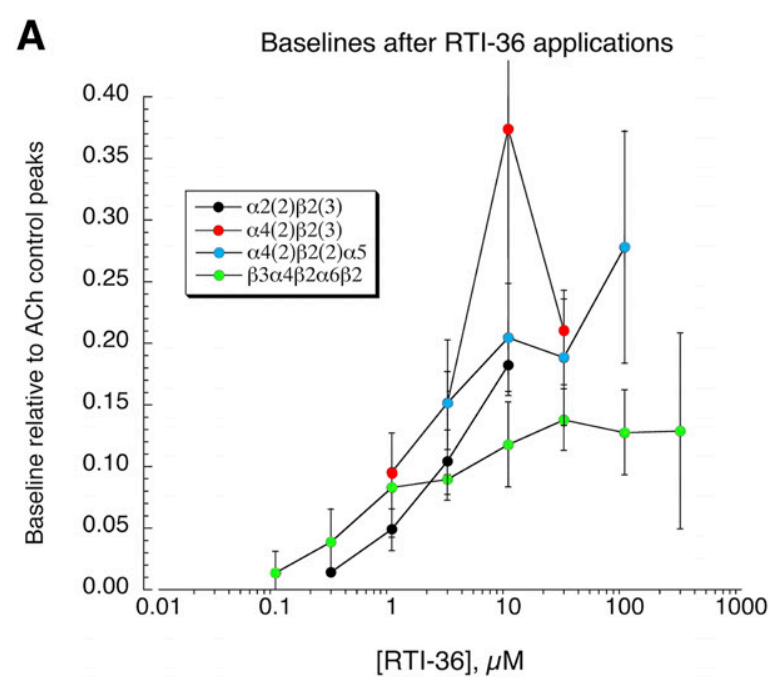

B

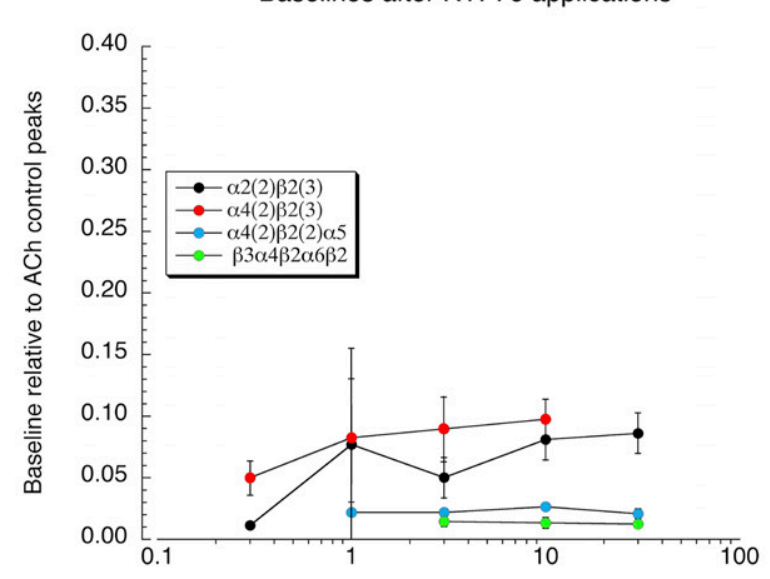

[RTI-76], $\mu \mathrm{M}$
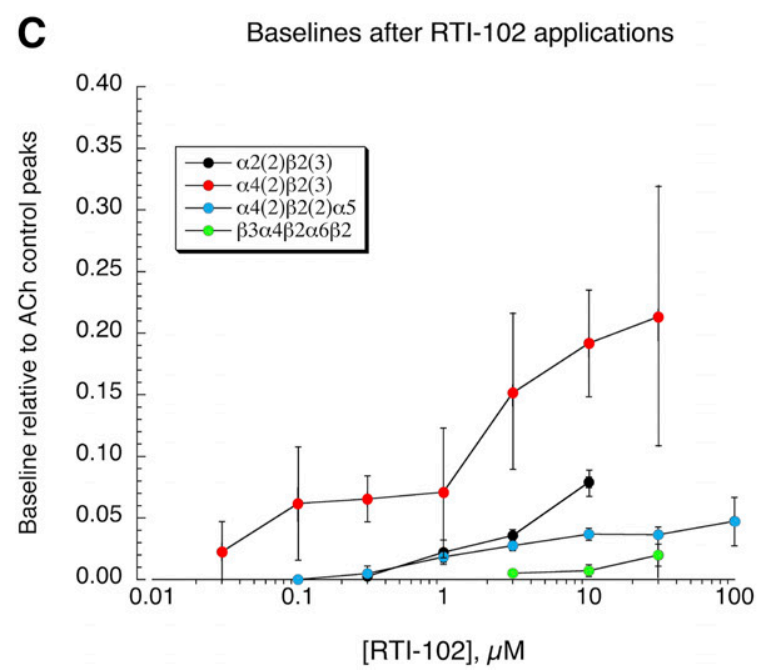

Fig. 9. Baseline shifts with test compounds and sensitive receptor subtypes. (A) Persistent currents stimulated by RTI-36, measured as baseline increases averaged over 30 -second periods beginning 4 minutes after the 6-second application of RTI-36 at the indicated concentrations. Baseline increases were calculated relative to the peak current amplitudes people) that have not been chronically exposed to nicotine, are the $\alpha 4$ and $\alpha 2$ receptors primarily in the LS $3 \alpha: 2 \beta$ configuration, or are they mixtures of LS and HS subtypes? Do the ratios vary based on neuronal subtypes or locations in the brain? In vitro studies have shown that outside the brain, with tissuecultured nonneuronal cells (Srinivasan et al., 2011) and Xenopus oocytes (Kuryatov et al., 2005; Zwart et al., 2006), nicotine can act as a molecular chaperone, selectively increasing the surface expression of HS receptors. It is an attractive but unproven hypothesis that this mechanism in part provides the basis for the upregulation of nAChR function in smokers and may relate to nicotine dependence. Although there is evidence that $\mathrm{nAChR}$ on striatal synaptosomes consist of both HS and LS types (Marks et al., 2010), it is not clear that this was due strictly to populations with different subunit stoichiometry, rather than different subunit composition (Grady et al., 2010). Furthermore, the composition of the mixed receptor subtypes did not seem significantly different in animals that had received chronic nicotine exposure.

The measurements of macroscopic currents from large populations of receptors provide only limited insights into the underlying molecular processes, and the fact that we are making our observations on time scales of seconds to minutes rather than the millisecond time scale of single-channel transitions is a further limitation. Even with our control ACh responses, we know that it takes several seconds for the full concentration of agonist to be delivered, and what we record is a process in which channels are both activating and desensitizing at the same time. Our peak currents represent the point at which this balance between activation and desensitization is further perturbed as the agonist begins to be washed out of the bath (Papke, 2010). However, in the present studies, the data suggest that ligand-receptor interactions outlast the presence of free ligand in solution, supporting the hypothesis that the ligands stay bound to the receptors long enough to account for the persistent currents of the HS receptors as well as the desensitization of LS receptors to subsequent $\mathrm{ACh}$ applications.

A very minimal model for nAChR activation and desensitization is shown in Figure 11. The model assumes that agonist (A) binding promotes conformational changes in the receptor $(\mathrm{R})$ associated with the channel activated state $\left(\mathrm{AR}^{*}\right)$ or conversion to a threshold desensitized state $\left(\mathrm{AD}_{1}\right)$ and a stable desensitized state $\left(\mathrm{AD}_{2}\right)$ observed in the earliest study of nAChR desensitization (Katz and Thesleff, 1957). The rates and conformational equilibria between these states will necessarily depend on the properties of the specific ligands and receptors. Single channels recorded at high (saturating) concentrations of ACh reveal multiple levels of desensitization associated with full occupancy of the agonist binding sites

\footnotetext{
of the initial ACh controls from the same cells. (B) Persistent currents stimulated by RTI-76, measured as baseline increases averaged over 30second periods beginning 4 minutes after the 6-second application of RTI76 at the indicated concentrations. Baseline increases were calculated relative to the peak current amplitudes of the initial $\mathrm{ACh}$ controls from the same cells. (C) Persistent currents stimulated by RTI-102, measured as baseline increases averaged over 30 -second periods beginning 4 minutes after the 6-second application of RTI-102 at the indicated concentrations. Baseline increases were calculated relative to the peak current amplitudes of the initial ACh controls from the same cells. (A-C) All points are the average of five to eight cells ( \pm S.E.M.).
} 

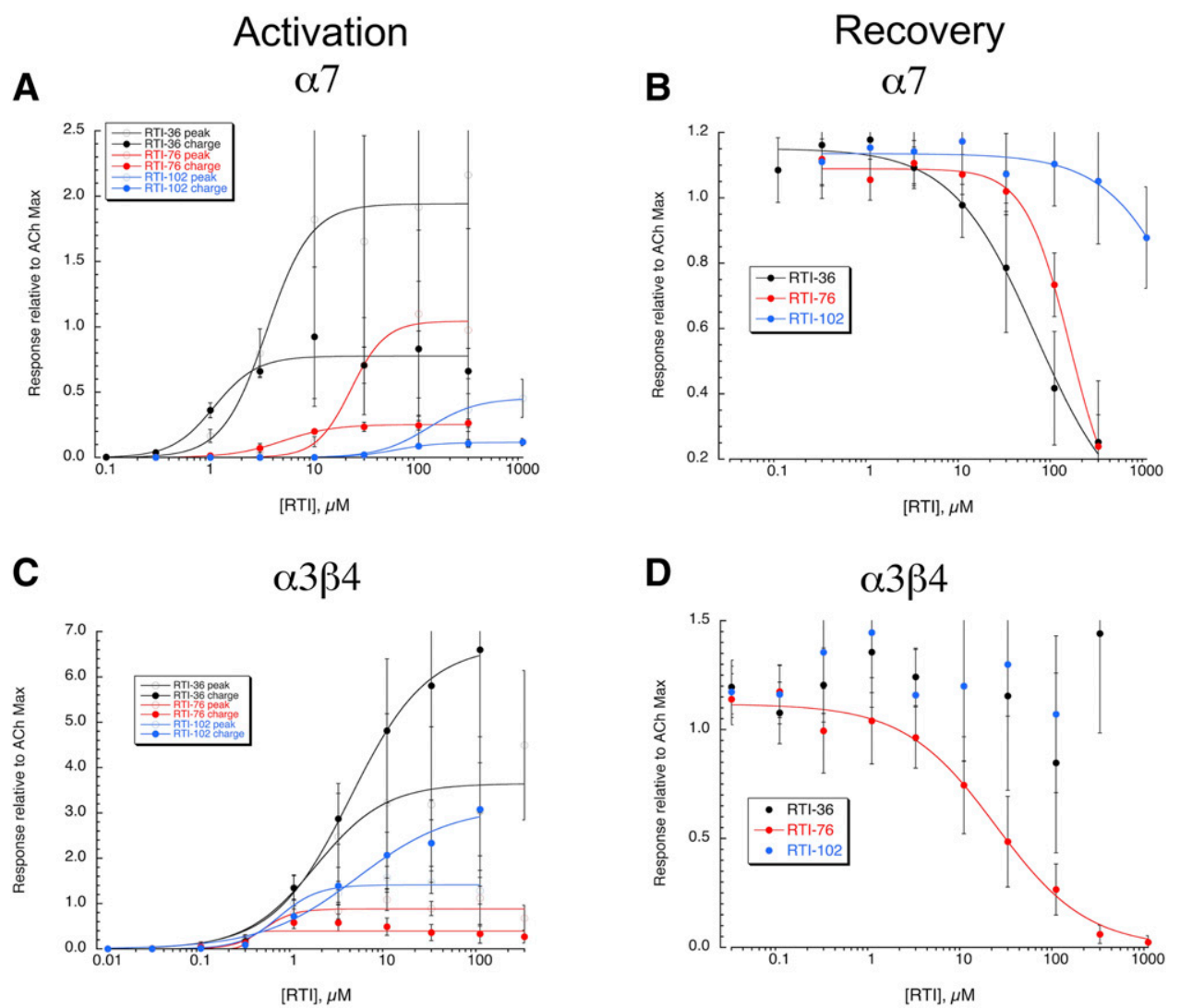

Fig. 10. Concentration-response studies of $\alpha 7$ and $\alpha 3 \beta 4$ receptors. (A) Activation of $\alpha 3 \beta 4$ receptors by varying concentration of the epibatidine analogs. Responses were calculated as both peak currents (open circles) and net charge (filled circles) integrated over 120-second periods starting with the drug applications. All data were normalized to the initial $100 \mu \mathrm{M}$ ACh controls obtained from the same cells. Each point is the average of five to eight cells $\left( \pm\right.$ S.D.). Note that $100 \mu \mathrm{M}$ ACh is the peak current $\mathrm{EC}_{39}$ for this receptor subtype as determined in previous experiments (Papke et al., 2013). Therefore, to display the data relative to ACh maximum, values normalized to ACh controls were multiplied by 0.39 . (B) Responses evoked by $100 \mu \mathrm{M}$ ACh 4.5 minutes after the application of the epibatidine analogs at the indicated concentrations. (C) Activation of $\alpha 7$ receptors by varying concentration of the epibatidine analogs. Responses were calculated as both peak currents (open circles) and net charge (filled circles) integrated over 120-second periods starting with the drug applications. All data were normalized to the initial $60 \mu \mathrm{M}$ ACh controls obtained from the same cells. Each point is the average of five to eight cells ( \pm S.D.). Note that $60 \mu \mathrm{M}$ ACh is the peak current $\mathrm{EC}_{80}$ for this receptor subtype as determined in previous experiments (Papke et al., 2013). Therefore, to display the data relative to ACh maximum, values normalized to ACh controls were multiplied by 0.80 on this scale. (D) Responses evoked by $60 \mu \mathrm{M}$ ACh 4.5 minutes after the application of the epibatidine analogs at the indicated concentrations. For curve fit values see Table 3. See Supplemental Data for the $n$ values of each point and alternative plots and fits of the data utilizing the replicate measurements at each concentration.

(Sine and Steinbach, 1987; Colquhoun and Ogden, 1988), and D states may be associated with both liganded and unliganded receptors. This model assumes a certain amount of equilibration among the states, which is appropriate given the slow rate of solution exchange in our experimental system (Papke, 2010) or when drugs are delivered in vivo. However, in vivo the delivery of the natural agonist ACh may be very rapid and transient. With rapid application of ACh, $\alpha 4 \beta 2$ receptors initially show a very high probability of opening $(>80 \%)$ but very rapidly begin to equilibrate with desensitized states $(\mathrm{Li}$ and Steinbach, 2010).

Consider the contrasting responses of LS $\alpha 4 \beta 2$ and HS $\alpha 4 \beta 2$ to $10 \mu \mathrm{M}$ RTI-102 shown in Figure 3, C and D, respectively. RTI-102 is ineffective at activating this receptor, so that the rate for conversion from $\mathrm{AR}$ to $\mathrm{AR}^{*}$ is very low (as represented by line thinness) especially as compared with the rate from $\mathrm{AR}$ to $A D_{1}$. The rates between $A D_{1}$ and $A D_{2}$ favor receptors in $A D_{2}$, accounting from the decreased response to subsequent applications of ACh. An alternative interpretation, that LS $\alpha 4 \beta 2$ receptors simply remain in the AR state with RTI-102 bound, is not likely since the AR state is a low-affinity state, which is not consistent with the prolonged effect of RTI-102 applications.
For RTI-102 and HS $\alpha 4 \beta 2$ receptors, the activation rate from $\mathrm{AR}$ to $\mathrm{AR}^{*}$ is relatively high, and receptors readily return to the $A R$ state from the $D_{1}$ state and only slowly convert to the $\mathrm{D}_{2}$ state. Having intermittent bouts of $\mathrm{nAChR}$ activation under conditions when receptors are predominantly desensitized has been referred to as "smoldering" (Campling et al., 2013). In the case of these HS receptor responses to the epibatidine analogs, the condition is perhaps closer to "wildfire." The fact that current is sustained after drug washout for HS receptors but not for LS, combined with the observation that the LS receptors are reduced in responses to subsequent $\mathrm{ACh}$ applications, indicates that the drugs do stay bound to the orthosteric sites of both receptors but that the equilibrium between activation and desensitization is different.

In considering why the $\mathrm{HS} \alpha 4 \beta 2$ and $\alpha 2 \beta 2$ receptors, and to a lesser degree the $\alpha 5$ - and $\alpha 6$-containing receptors, manifest these persistent currents, it is tempting to speculate that it may be as much about the presence of the putative low-affinity $\alpha-\alpha$ binding site on the LS forms of the receptors as about specific effects of the alternative accessory subunits. Perhaps binding of the analogs to the $\alpha-\alpha$ site somehow puts the 


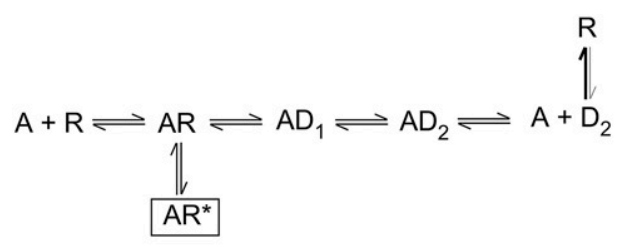

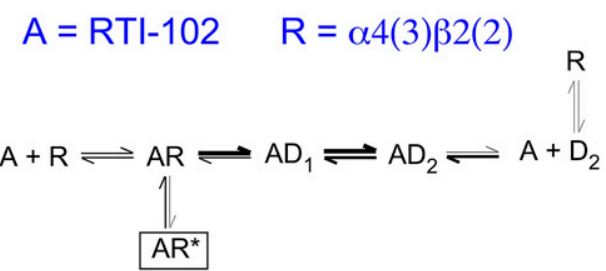

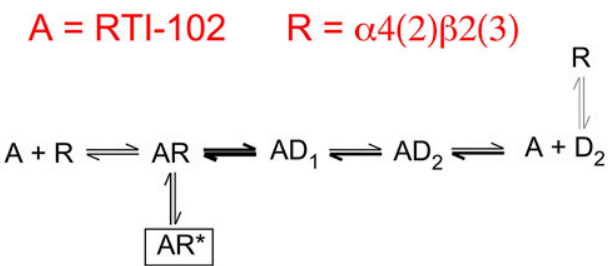

Fig. 11. nAChR activation and desensitization. Shown on top is a simplified scheme for agonist (A) activation and desensitization of nAChR. In this reduced model (Papke and Lindstrom, 2020) the binding of a single agonist (AR state) promotes conformation change to either the open channel form $\left(\mathrm{AR}^{*}\right)$ or a desensitized state $\left(\mathrm{AD}_{1}\right)$ that can, with a certain probability, revert back to the activatible $\mathrm{AR}$ state or a more stable desensitized $\left(\mathrm{AD}_{2}\right)$ state. The $\mathrm{D}$ states are known to bind agonists with higher affinity than the resting closed $(\mathrm{R})$ states of the receptors. Once agonist dissociates from receptors in the $\mathrm{AD}_{2}$ state $\left(\mathrm{D}_{2}\right)$, the receptors retain that high affinity and therefore may rebind agonist and return to the $\mathrm{AD}_{2}$ state, or if the agonist concentration is low for a long enough period of time, the receptors may revert back to the low-affinity $R$ state. Shown in the middle, for the LS $\alpha 4(3) \beta 2(2)-R T I-102$ drug-receptor combination, there is little activation from the $\mathrm{AR}$ to the $\mathrm{AR}^{*}$ state, and equilibrium favors the $\mathrm{D}_{2}$ state over the $\mathrm{D}_{1}$ state. Shown at the bottom is a possible way this model might explain the persistent currents of HS $\alpha 4(2) \beta 2(3)$ receptors stimulated by RTI-102 (see Fig. 4). Relatively increased rate constants are represented by thicker arrows. For this drug/receptor combination, there may be rapid conversion back and forth between $\mathrm{AR}$ and $\mathrm{AD}_{1}$ states and relatively slow conversion from $\mathrm{AD}_{1}$ to $\mathrm{AD}_{2}$ states.

brakes on channel activation or acts to stabilize receptors in the $\mathrm{D}_{2}$ state.

These compounds were initially found to have relatively low efficacy in models of acute analgesia, hypolocomotion, and hypothermia (Carroll et al., 2004, 2005, 2010) (Table 2). Subsequent studies have found them all to exert agonist activity (Rodriguez et al., 2014), with rank order apparent efficacy RT-36 > RTI-76 > RTI-102 in a model of nicotine's subjective effects and potential abuse-related effects. It may be that the different apparent efficacies exhibited by these epibatidine analogs in mice reflect the relative contribution of the LS $\alpha 4 \beta 2$ and HS $\alpha 4 \beta 2$ forms of nAChRs to the effects of each compound. Some of these compounds, RTI-36 in particular, have a relatively long duration of in vivo action, and it remains to be determined whether $n A C h R$ channel kinetics, in addition to drug metabolism, may be responsible for these prolonged actions. Moreover, it remains to be determined what the activity of these and other epibatidine analogs in the RTI series will be in other assays of $\mathrm{nAChR}$ function, including
TABLE 4

Major proposed roles of nAChR subtypes in mediating some well known behavioral and physiologic effects of nicotine in preclinical studies

\begin{tabular}{lll}
\hline Subtype & \multicolumn{1}{c}{ Function } & \multicolumn{1}{c}{ References } \\
\hline$\alpha 4(2) \beta 2(3)$ & Nicotine addiction & Picciotto et al., 1998 \\
$\alpha 4(3) \beta 2(2)$ & $\begin{array}{l}\text { Nociception } \\
\text { Hypothermia }\end{array}$ & $\begin{array}{l}\text { Damaj et al., 2007 } \\
\text { Marks, 2013 }\end{array}$ \\
& $\begin{array}{l}\text { Hypolocomotion } \\
\text { Cognition }\end{array}$ & Terry and Callahan, 2019 \\
& Nicotine addiction & Jackson et al., 2010 \\
$\alpha 4(2) \beta 2(2) \alpha 5$ & Nociception & Fowler et al., 2011 \\
& Hypothermia & \\
& Hypolocomotion & \\
$\alpha 3 \beta 4$ & Nicotine addiction & Jackson et al., 2013 \\
$\alpha 2(2) \beta 2(3)$ & Nicotine addiction & Upton and Lotfipour, 2015 \\
$\alpha 2(3) \beta 2(2)$ & Cognition & Lotfipour et al., 2017 \\
$\beta 3 \alpha 4 \beta 2 \alpha 6 \beta 2$ & Nicotine addiction & Yang et al., 2009 \\
& & Picciotto and Kenny, 2013 \\
$\alpha 7$ & Nociception & Bagdas et al., 2018 \\
& Cognition & Terry and Callahan, 2019 \\
\hline
\end{tabular}

preclinical assessments of nicotine addiction and dependence. The activity profiles we report here may serve to shed light on the molecular basis for those behaviors, especially when considered in the context of other published studies (Table 4) that have provided basic associations between receptor subtypes and specific behavioral and physiologic effects. Our work, however, highlights the need for finer analyses of receptor subtypes that take into account not only receptor subunits but also subunit stoichiometry.

\section{Acknowledgments}

We thank Marina Picciotto (Yale University) for helpful comments and Fernando Valenzuela, (Department of Neurosciences, University of New Mexico, Albuquerque, NM) for conducting additional statistical tests.

\section{Authorship Contributions}

Participated in research design: Corrie, Stokes, Wilkerson, McMahon, Papke.

Conducted experiments: Corrie, Stokes.

Contributed new reagents or analytic tools: Carroll.

Performed data analysis: Corrie, Stokes, Papke.

Wrote or contributed to the writing of the manuscript: Stokes, McMahon, Papke.

\section{References}

Abdrakhmanova GR, Damaj MI, Carroll FI, and Martin BR (2006) 2-Fluoro-3-(4nitro-phenyl)deschloroepibatidine is a novel potent competitive antagonist of human neuronal alpha4beta2 nAChRs. Mol Pharmacol 69:1945-1952.

Anderson DJ, Williams M, Pauly JR, Raszkiewicz JL, Campbell JE, Rotert G, Surber B, Thomas SB, Wasicak J, Arneric SP, et al. (1995) Characterization of [3H]ABT418: a novel cholinergic channel ligand. J Pharmacol Exp Ther 273:1434-1441.

Badio B and Daly JW (1994) Epibatidine, a potent analgetic and nicotinic agonist. Mol Pharmacol 45:563-569.

Bagdas D, Gurun MS, Flood P, Papke RL, and Damaj MI (2018) New insights on neuronal nicotinic acetylcholine receptors as targets for pain and inflammation: a focus on $\alpha 7$ nAChRs. Curr Neuropharmacol 16:415-425.

Campling BG, Kuryatov A, and Lindstrom J (2013) Acute activation, desensitization and smoldering activation of human acetylcholine receptors. PLoS One 8:e79653.

Carbone AL, Moroni M, Groot-Kormelink PJ, and Bermudez I (2009) Pentameric concatenated (alpha4)(2)(beta2)(3) and (alpha4)(3)(beta2)(2) nicotinic acetylcholine receptors: subunit arrangement determines functional expression. Br J Pharmacol 156:970-981.

Carroll FI (2009) Epibatidine analogs synthesized for characterization of nicotinic pharmacophores-a review. Heterocycles 79:99-120.

Carroll FI, Ma W, Deng L, Navarro HA, Damaj MI, and Martin BR (2010) Synthesis, nicotinic acetylcholine receptor binding, and antinociceptive properties of 3 ' (substituted phenyl)epibatidine analogues. Nicotinic partial agonists. J Nat Prod 73:306-312.

Carroll FI, Ma W, Yokota Y, Lee JR, Brieaddy LE, Navarro HA, Damaj MI, and Martin BR (2005) Synthesis, nicotinic acetylcholine receptor binding, and antinociceptive properties of 3 '-substituted deschloroepibatidine analogues. Novel nicotinic antagonists. J Med Chem 48:1221-1228. 
Carroll FI, Ware R, Brieaddy LE, Navarro HA, Damaj MI, and Martin BR (2004) Synthesis, nicotinic acetylcholine receptor binding, and antinociceptive properties of 2 '-fluoro-3'-(substituted phenyl)deschloroepibatidine analogues. Novel nicotinic antagonist. J Med Chem 47:4588-4594.

Colquhoun D and Ogden DC (1988) Activation of ion channels in the frog end-plate by high concentrations of acetylcholine. $J$ Physiol 395:131-159.

Damaj MI, Fonck C, Marks MJ, Deshpande P, Labarca C, Lester HA, Collins AC, and Martin BR (2007) Genetic approaches identify differential roles for alpha4beta $2 *$ nicotinic receptors in acute models of antinociception in mice. J Pharmacol Exp Ther 321:1161-1169.

David R, Ciuraszkiewicz A, Simeone X, Orr-Urtreger A, Papke RL, McIntosh JM, Huck S, and Scholze P (2010) Biochemical and functional properties of distinct nicotinic acetylcholine receptors in the superior cervical ganglion of mice with targeted deletions of nAChR subunit genes. Eur J Neurosci 31 978-993.

Drenan RM, Grady SR, Steele AD, McKinney S, Patzlaff NE, McIntosh JM, Marks MJ, Miwa JM, and Lester HA (2010) Cholinergic modulation of locomotion and striatal dopamine release is mediated by alpha6alpha4* nicotinic acetylcholine receptors. J Neurosci 30:9877-9889.

Fowler CD, Lu Q, Johnson PM, Marks MJ, and Kenny PJ (2011) Habenular $\alpha 5$ nicotinic receptor subunit signalling controls nicotine intake. Nature 471:597-601.

Gerzanich V, Kuryatov A, Anand R, and Lindstrom J (1997) "Orphan" alpha6 nicotinic AChR subunit can form a functional heteromeric acetylcholine receptor. Mol Pharmacol 51:320-327.

Gerzanich V, Peng X, Wang F, Wells G, Anand R, Fletcher S, and Lindstrom J (1995) Comparative pharmacology of epibatidine: a potent agonist for neuronal nicotinic acetylcholine receptors. Mol Pharmacol 48:774-782.

Gerzanich V, Wang F, Kuryatov A, and Lindstrom J (1998) Alpha 5 Subunit alters desensitization, pharmacology, $\mathrm{Ca}++$ permeability and $\mathrm{Ca}++$ modulation of human neuronal alpha 3 nicotinic receptors. J Pharmacol Exp Ther 286:311-320.

Gotti C, Guiducci S, Tedesco V, Corbioli S, Zanetti L, Moretti M, Zanardi A, Rimondini R, Mugnaini M, Clementi F, et al. (2010) Nicotinic acetylcholine receptors in the mesolimbic pathway: primary role of ventral tegmental area alpha6beta $2 *$ receptors in mediating systemic nicotine effects on dopamine release, locomotion, and reinforcement. $J$ Neurosci 30:5311-5325.

Grady SR, Salminen O, McIntosh JM, Marks MJ, and Collins AC (2010) Mouse striatal dopamine nerve terminals express alpha4alpha5beta2 and two stoichiometric forms of alpha4beta $2 *$-nicotinic acetylcholine receptors. $J$ Mol Neurosci 40 91-95.

Halevi S, Yassin L, Eshel M, Sala F, Sala S, Criado M, and Treinin M (2003) Conservation within the RIC-3 gene family. Effectors of mammalian nicotinic acetylcholine receptor expression. J Biol Chem 278:34411-34417.

Han ZY, Le Novère N, Zoli M, Hill JA Jr., Champtiaux N, and Changeux JP (2000) Localization of nAChR subunit mRNAs in the brain of Macaca mulatta. Eur $J$ Neurosci 12:3664-3674.

Han ZY, Zoli M, Cardona A, Bourgeois JP, Changeux JP, and Le Novère N (2003) Localization of $[3 \mathrm{H}]$ nicotine, [3H]cytisine, [3H]epibatidine, and [125I]alphabungarotoxin binding sites in the brain of Macaca mulatta. J Comp Neurol 461: $49-60$

Houghtling RA, Dávila-García MI, and Kellar KJ (1995) Characterization of (+/-)(-) $[3 \mathrm{H}]$ epibatidine binding to nicotinic cholinergic receptors in rat and human brain. Mol Pharmacol 48:280-287.

Jackson KJ, Marks MJ, Vann RE, Chen X, Gamage TF, Warner JA, and Damaj MI (2010) Role of alpha5 nicotinic acetylcholine receptors in pharmacological and behavioral effects of nicotine in mice. J Pharmacol Exp Ther 334:137-146.

Jackson KJ, McIntosh JM, Brunzell DH, Sanjakdar SS, and Damaj MI (2009) The role of alpha6-containing nicotinic acetylcholine receptors in nicotine reward and withdrawal. J Pharmacol Exp Ther 331:547-554.

Jackson KJ, Sanjakdar SS, Muldoon PP, McIntosh JM, and Damaj MI (2013) The $\alpha 3 \beta 4^{*}$ nicotinic acetylcholine receptor subtype mediates nicotine reward and physical nicotine withdrawal signs independently of the $\alpha 5$ subunit in the mouse. Neuropharmacology 70:228-235.

Jain A, Kuryatov A, Wang J, Kamenecka TM, and Lindstrom J (2016) Unorthodox acetylcholine binding sites formed by $\alpha 5$ and $\beta 3$ accessory subunits in $\alpha 4 \beta 2^{*}$ nicotinic acetylcholine receptors. J Biol Chem 291:23452-23463.

Katz B and Thesleff S (1957) A study of the desensitization produced by acetylcholine at the motor end-plate. $J$ Physiol 138:63-80.

Kuryatov A and Lindstrom J (2011) Expression of functional human $\alpha 6 \beta 2 \beta 3^{*}$ acetylcholine receptors in Xenopus laevis oocytes achieved through subunit chimeras and concatamers. Mol Pharmacol 79:126-140.

Kuryatov A, Luo J, Cooper J, and Lindstrom J (2005) Nicotine acts as a pharmacological chaperone to up-regulate human alpha4beta2 acetylcholine receptors. $\mathrm{Mol}$ Pharmacol 68:1839-1851.

Kuryatov A, Olale F, Cooper J, Choi C, and Lindstrom J (2000) Human alpha6 AChR subtypes: subunit composition, assembly, and pharmacological responses. Neuropharmacology 39:2570-2590.

Kuryatov A, Onksen J, and Lindstrom J (2008) Roles of accessory subunits in alpha4beta2(*) nicotinic receptors. Mol Pharmacol 74:132-143.

Li P and Steinbach JH (2010) The neuronal nicotinic alpha4beta2 receptor has a high maximal probability of being open. $\mathrm{Br} J$ Pharmacol 160:1906-1915.

Liu L, Zhao-Shea R, McIntosh JM, Gardner PD, and Tapper AR (2012) Nicotine persistently activates ventral tegmental area dopaminergic neurons via nicotinic acetylcholine receptors containing $\alpha 4$ and $\alpha 6$ subunits. Mol Pharmacol 81:541-548.

Lotfipour S, Mojica C, Nakauchi S, Lipovsek M, Silverstein S, Cushman J, Tirtorahardjo J, Poulos A, Elgoyhen AB, Sumikawa K, et al. (2017) $\alpha 2^{*}$ Nicotinic acetylcholine receptors influence hippocampus-dependent learning and memory in adolescent mice. Learn Mem 24:231-244.

Lucero LM, Weltzin MM, Eaton JB, Cooper JF, Lindstrom JM, Lukas RJ, and Whiteaker $\mathrm{P}(2016)$ Differential $\alpha 4(+) /(-) \beta 2$ agonist-binding site contributions to $\alpha 4 \beta 2$ nicotinic acetylcholine receptor function within and between isoforms. $J$ Biol Chem 291:2444-2459.

Luetje CW and Patrick J (1991) Both alpha- and beta-subunits contribute to the agonist sensitivity of neuronal nicotinic acetylcholine receptors. $J$ Neurosci 11: 837-845

Marks MJ (2013) Genetic matters: thirty years of progress using mouse models in nicotinic research. Biochem Pharmacol 86:1105-1113.

Marks MJ, Meinerz NM, Brown RW, and Collins AC (2010) 86Rb+ efflux mediated by alpha4beta $2 *$-nicotinic acetylcholine receptors with high and low-sensitivity to stimulation by acetylcholine display similar agonist-induced desensitization. Biochem Pharmacol 80:1238-1251.

Moroni M, Zwart R, Sher E, Cassels BK, and Bermudez I (2006) alpha4beta2 nicotinic receptors with high and low acetylcholine sensitivity: pharmacology, stoichiometry, and sensitivity to long-term exposure to nicotine. Mol Pharmacol 70 $755-768$.

Nelson ME, Kuryatov A, Choi CH, Zhou Y, and Lindstrom J (2003) Alternate stoichiometries of alpha4beta2 nicotinic acetylcholine receptors. Mol Pharmacol 63: 332-341.

Ondachi PW, Castro AH, Bartkowiak JM, Luetje CW, Damaj MI, Mascarella SW, Navarro HA, and Carroll FI (2014) Synthesis, nicotinic acetylcholine receptor binding, and antinociceptive properties of 2 '-fluoro-3'-(substituted pyridinyl)-7deschloroepibatidine analogues. J Med Chem 57:836-848.

Papke RL (2006) Estimation of both the potency and efficacy of alpha7 nAChR agonists from single-concentration responses. Life Sci 78:2812-2819.

Papke RL (2010) Tricks of perspective: insights and limitations to the study of macroscopic currents for the analysis of nAChR activation and desensitization. J Mol Neurosci 40:77-86.

Papke RL (2014) Merging old and new perspectives on nicotinic acetylcholine receptors. Biochem Pharmacol 89:1-11.

Papke RL, Boulter J, Patrick J, and Heinemann S (1989) Single-channel currents of rat neuronal nicotinic acetylcholine receptors expressed in Xenopus oocytes. Neuron 3:589-596.

Papke RL, Brunzell DH, and De Biasi M (2020) Cholinergic receptors and addiction. Curr Top Behav Neurosci DOI: 10.1007/7854 2020 139 [published ahead of print].

Papke RL and Heinemann SF (1991) The role of the beta 4-subunit in determining the kinetic properties of rat neuronal nicotinic acetylcholine alpha 3-receptors. $J$ Physiol 440:95-112.

Papke RL and Lindstrom JM (2020) Nicotinic acetylcholine receptors: conventional and unconventional ligands and signaling. Neuropharmacology 168:108021.

Papke RL and Porter Papke JK (2002) Comparative pharmacology of rat and human alpha7 nAChR conducted with net charge analysis. Br J Pharmacol 137:49-61.

Papke RL and Stokes C (2010) Working with OpusXpress: methods for high volume oocyte experiments. Methods 51:121-133.

Papke RL, Stokes C, Muldoon P, and Imad Damaj M (2013) Similar activity of mecamylamine stereoisomers in vitro and in vivo. Eur J Pharmacol 720: 264-275.

Papke RL, Thinschmidt JS, Moulton BA, Meyer EM, and Poirier A (1997) Activation and inhibition of rat neuronal nicotinic receptors by ABT-418. Br J Pharmacol 120: 429-438.

Papke RL, Wecker L, and Stitzel JA (2010) Activation and inhibition of mouse muscle and neuronal nicotinic acetylcholine receptors expressed in Xenopus oocytes. $J$ Pharmacol Exp Ther 333:501-518.

Picciotto MR and Kenny PJ (2013) Molecular mechanisms underlying behaviors related to nicotine addiction. Cold Spring Harb Perspect Med 3:a012112.

Picciotto MR, Zoli M, Rimondini R, Léna C, Marubio LM, Pich EM, Fuxe K, and Changeux JP (1998) Acetylcholine receptors containing the beta2 subunit are involved in the reinforcing properties of nicotine. Nature 391: 173-177.

Rodriguez JS, Cunningham CS, Moura FB, Ondachi P, Carroll FI, and McMahon LR (2014) Discriminative stimulus and hypothermic effects of some derivatives of the nAChR agonist epibatidine in mice. Psychopharmacology (Berl) 231:4455-4466.

Sala F, Nistri A, and Criado M (2008) Nicotinic acetylcholine receptors of adrenal chromaffin cells. Acta Physiol (Oxf) 192:203-212.

Sala M, Braida D, Pucci L, Manfredi I, Marks MJ, Wageman CR, Grady SR, Loi B Fucile S, Fasoli F, et al. (2013) CC4, a dimer of cytisine, is a selective partial agonist at $\alpha 4 \beta 2 / \alpha 6 \beta 2 \mathrm{nAChR}$ with improved selectivity for tobacco smoking cessation. Br J Pharmacol 168:835-849.

Sanjakdar SS, Maldoon PP, Marks MJ, Brunzell DH, Maskos U, McIntosh JM, Bowers MS, and Damaj MI (2015) Differential roles of $\alpha 6 \beta 2 *$ and $\alpha 4 \beta 2 *$ neuronal nicotinic receptors in nicotine- and cocaine-conditioned reward in mice. Neuropsychopharmacology 40:350-360.

Sine SM and Steinbach JH (1987) Activation of acetylcholine receptors on clonal mammalian BC3H-1 cells by high concentrations of agonist. J Physiol 385: 325-359

Srinivasan R, Pantoja R, Moss FJ, Mackey ED, Son CD, Miwa J, and Lester HA (2011) Nicotine up-regulates alpha4beta2 nicotinic receptors and ER exit sites via stoichiometry-dependent chaperoning. J Gen Physiol 137:59-79.

Stokes C and Papke RL (2012) Use of an $\alpha 3 \beta 4$ nicotinic acetylcholine receptor subunit concatamer to characterize ganglionic receptor subtypes with specific subunit composition reveals species-specific pharmacologic properties. Neuropharmacology 63:538-546.

Stokes C, Treinin M, and Papke RL (2015) Looking below the surface of nicotinic acetylcholine receptors. Trends Pharmacol Sci 36:514-523.

Terry AV and Callahan PM (2019) Nicotinic acetylcholine receptor ligands, cognitive function, and preclinical approaches to drug discovery. Nicotine Tob Res 21: $383-394$

Upton M and Lotfipour S (2015) $\alpha 2$-Null mutant mice have altered levels of neuronal activity in restricted midbrain and limbic brain regions during nicotine withdrawal as demonstrated by cfos expression. Biochem Pharmacol 97:558-565. 
Wada E, Wada K, Boulter J, Deneris E, Heinemann S, Patrick J, and Swanson LW (1989) Distribution of alpha 2, alpha 3, alpha 4, and beta 2 neuronal nicotinic receptor subunit mRNAs in the central nervous system: a hybridization histochemical study in the rat. J Comp Neurol 284:314-335.

Xiao Y, Fan H, Musachio JL, Wei ZL, Chellappan SK, Kozikowski AP, and Kellar KJ (2006) Sazetidine-A, a novel ligand that desensitizes alpha4beta 2 nicotinic acetylcholine receptors without activating them. Mol Pharmacol $\mathbf{7 0}$ : 1454-1460.

Yang KC, Jin GZ, and Wu J (2009) Mysterious alpha6-containing nAChRs: function, pharmacology, and pathophysiology. Acta Pharmacol Sin 30:740-751.

Zhou Y, Nelson ME, Kuryatov A, Choi C, Cooper J, and Lindstrom J (2003) Human alpha4beta2 acetylcholine receptors formed from linked subunits. J Neurosci 23 : 9004-9015.
Zwart R, Broad LM, Xi Q, Lee M, Moroni M, Bermudez I, and Sher E (2006) 5-I A85380 and TC-2559 differentially activate heterologously expressed alpha4beta2 nicotinic receptors. Eur J Pharmacol 539:10-17.

Zwart R, Carbone AL, Moroni M, Bermudez I, Mogg AJ, Folly EA, Broad LM, Williams AC, Zhang D, Ding C, et al. (2008) Sazetidine-A is a potent and selective agonist at native and recombinant alpha 4 beta 2 nicotinic acetylcholine receptors. Mol Pharmacol 73:1838-1843.

Address correspondence to: Roger L. Papke, Department of Pharmacology and Therapeutics, University of Florida, P.O. Box 100267, Gainesville, FL 32610-0267. E-mail: rlpapke@ufl.edu 